\title{
Parametric study of a sustainable cooling system integrating phase change material energy storage for buildings
}

\section{Rami Zeinelabdein ${ }^{1}$ a b, Siddig Omer ${ }^{b}$ and Elamin Mohamed ${ }^{b}$ \\ (a) Department of Housing Studies, Faculty of Architecture, University of Khartoum, Al-Gamaa Ave, P.O. Box 321, Khartoum, Sudan \\ (b) Department of Architecture and Built Environment, Faculty of Engineering, the University of Nottingham, University Park, Nottingham NG7 2RD, UK}

\section{Abstract}

Free cooling of buildings uses the nocturnal outdoor air as a heat sink via a ventilation process. This could be performed by storing the night coolness for use during the daytime as appropriate. Due to the latent heat capacity, phase change material (PCM) could play an essential role in the effective operation of the free cooling systems by shifting the daytime peak load to the night. However, there is a scarceness on the technology application in hot climates. This paper presents results of a parametric investigation into the application of PCMs as thermal energy storage (TES) to provide sustainable cooling to buildings in hot arid climate by making use of the night-time free cooling. The proposed TES medium comprises an arrangement of metallic modules filled with RT28HC PCM. Numerous geometrical configurations and operational parameters have been assessed. A transient CFD simulation has been employed using ANSYS Fluent software. Validation of the numerical results with experimental data has shown a good agreement. The results have demonstrated that the temperature difference between the PCM and the air, at appropriate air flow rate would have a significant impact on the performance of the system. A free cooling system based on the proposed arrangement has the potential to meet around $42 \%$ of a typical building cooling load and has the ability to save up to $67 \%$ of building cooling energy load in summer season compared to conventional air-conditioning systems in hot arid climates.

Keywords

Free cooling; Energy storage; Phase change material; CFD modelling

\footnotetext{
${ }^{1}$ Corresponding author: R. Zeinelabdein

E-mail: rami.zeinelabdein@uofk.edu, rami.zein-elabdein@nottingham.ac.uk
} 


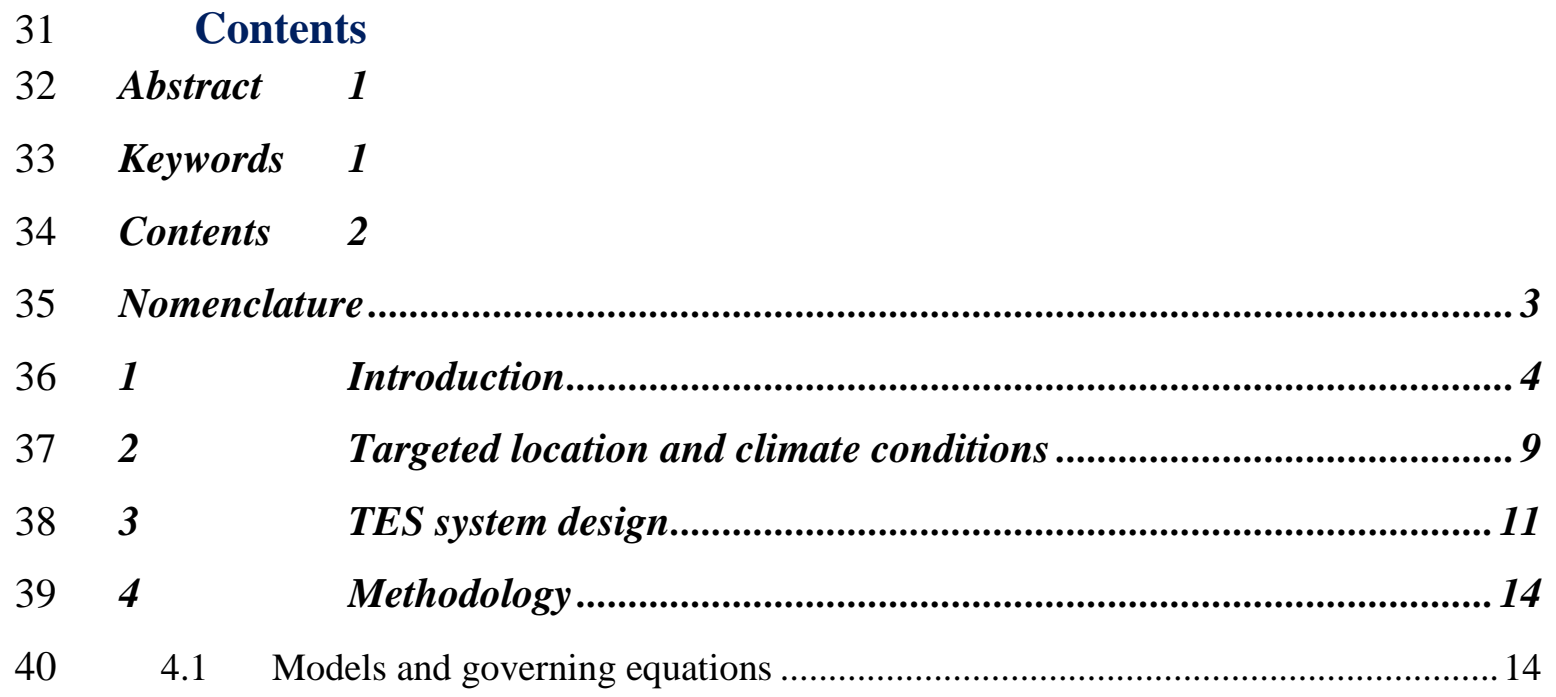

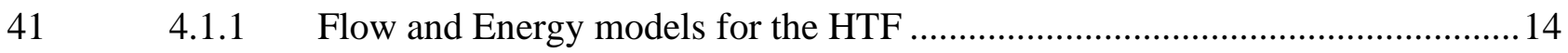

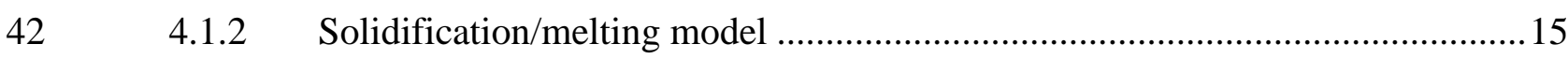

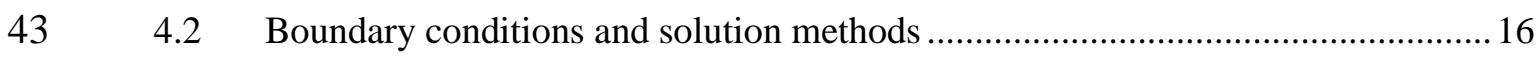

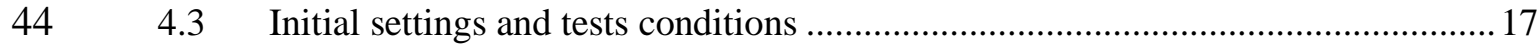

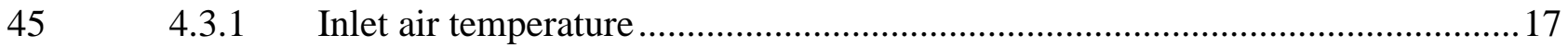

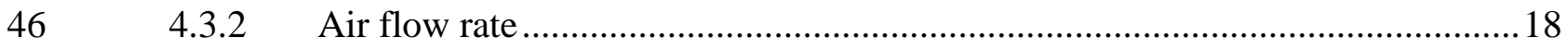

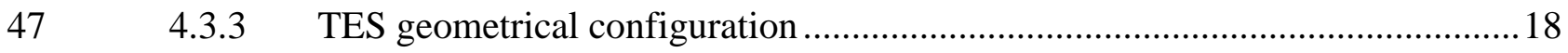

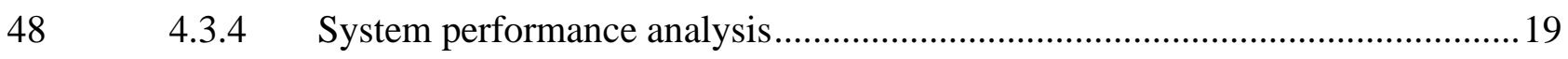

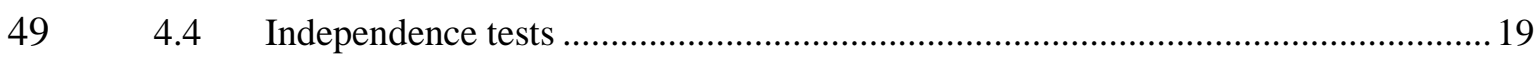

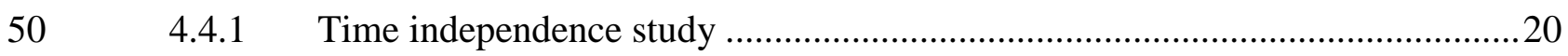

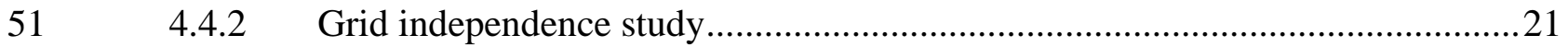

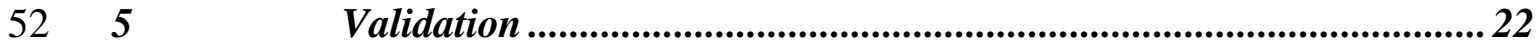

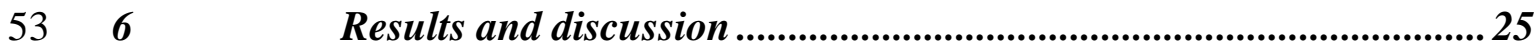

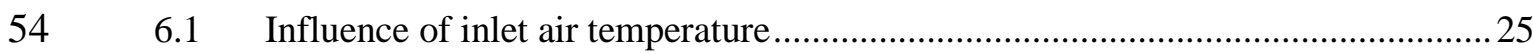

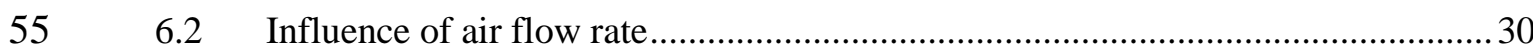

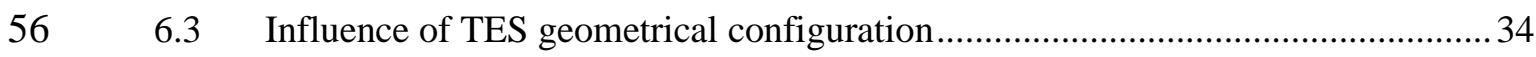

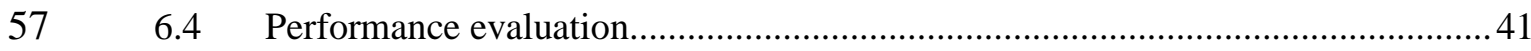

$58 \quad 6.4 .1 \quad$ Potential system performance under real climate conditions ..........................41

$59 \quad 6.4 .2$ Estimation of pressure and fan power consumption .....................................42

$60 \quad 6.4 .3 \quad$ Estimation of the system cooling capacity................................................... 43

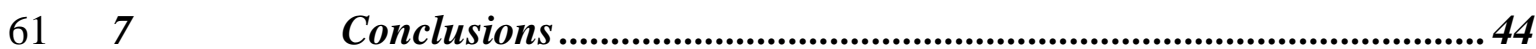

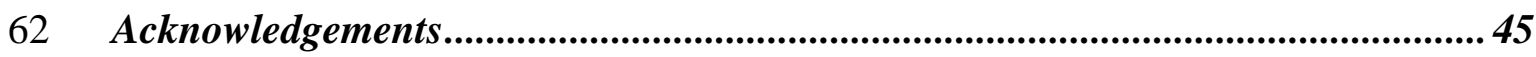

$63 \quad$ References 46 


\begin{tabular}{|c|c|c|}
\hline$\Delta h$ & Latent heat & $\mathrm{kJ} / \mathrm{kg}$ \\
\hline$\Delta p$ & Pressure drop & mbar \\
\hline$C p$ & Specific heat capacity & $\mathrm{kJ} / \mathrm{kg} . \mathrm{K}$ \\
\hline$d t$ & Temperature difference & $\mathrm{K}$ \\
\hline$E$ & Energy & Wh \\
\hline$g$ & Gravitational acceleration & $\mathrm{m} / \mathrm{s}^{2}$ \\
\hline$H$ & Specific enthalpy & $\mathrm{kJ} / \mathrm{kg}$ \\
\hline$h$ & Sensible heat & $\mathrm{kJ} / \mathrm{kg}$ \\
\hline$L$ & Latent heat storage capacity of a material & $\mathrm{kJ} / \mathrm{kg}$ \\
\hline$P$ & Power & $\mathrm{W}$ \\
\hline$p$ & Pressure & $\mathrm{Pa}$ \\
\hline$S$ & Source term & - \\
\hline$T$ & Temperature & ${ }^{\circ} \mathrm{C}$ \\
\hline$t$ & Time & $\mathrm{s}$ \\
\hline$u$ & Velocity of fluid & $\mathrm{m} / \mathrm{s}$ \\
\hline$\dot{V}$ & Volume flow rate & $\mathrm{L} / \mathrm{s}$ \\
\hline$v$ & Fluid velocity & $\mathrm{m} / \mathrm{s}$ \\
\hline$z$ & Height & $\mathrm{mm}$ \\
\hline \multicolumn{3}{|c|}{ Greek symbols } \\
\hline$\beta$ & Liquid fraction & - \\
\hline$\gamma$ & Kinematic viscosity & $\mathrm{m}^{2} / \mathrm{s}$ \\
\hline$\eta$ & Efficiency & $\%$ \\
\hline$\lambda$ & Thermal conductivity & $\mathrm{W} / \mathrm{m} \mathrm{K}$ \\
\hline$\rho$ & Density & $\mathrm{kg} / \mathrm{m}^{3}$ \\
\hline \multicolumn{3}{|c|}{ Abbreviations } \\
\hline 2D & Two-Dimensional & \\
\hline $\mathrm{ACH}$ & Air Change rate per Hour & \\
\hline $\mathrm{AC}$ & Air conditioning & \\
\hline CFD & Computational Fluid Dynamics & \\
\hline $\mathrm{COP}$ & Coffecient of Performance & \\
\hline HPC & High-Performance Computing & \\
\hline HTF & Heat Transfer Fluid & \\
\hline HVAC & Heating, Ventilation, and Air Conditioning & \\
\hline PCM & Phase Change Material & \\
\hline RANS & Reynolds-Averaged Navier-Stokes & \\
\hline SHS & Sensible Heat Storage & \\
\hline TES & Thermal Energy Storage & \\
\hline \multicolumn{3}{|c|}{ Subscripts } \\
\hline air, in & Inlet air & \\
\hline air, out & Outlet air & \\
\hline $\mathrm{amb}$ & Ambient & \\
\hline eff & Effective & \\
\hline liquidus & Liquidus point of PCM & \\
\hline ref & Reference & \\
\hline solidus & Solidus point of PCM & \\
\hline
\end{tabular}


67 Energy saving is one of the major issues these days due to increasing concerns about environmental related problems, as a result of the way the energy is used worldwide [1,2]. The building sector has a predominant contribution to global energy use by nearly $36 \%$ and is accountable for over $30 \%$ of the $\mathrm{CO}_{2}$ emissions [3]. In hot-arid regions, energy consumption in buildings is even much higher [4]. For instance, according to statistics of the Arab Union of Electricity [5], buildings in Sudan, Saudi Arabia, and Egypt (typical hot climate countries) are responsible for around $70 \%, 67 \%$, and $57 \%$ of the total energy consumption of the these countries, respectively, where more than $75 \%$ of this goes to the residential buildings.

A considerable rate of energy consumption in buildings is attributed to the utilisation of conventional heating, ventilating, and air-conditioning (HVAC) systems for indoor thermal comfort and air quality improvement [6,7]. In accordance with the International Energy Agency (IEA) [8], the universal energy use is anticipated to increase remarkably in future owing to the projected growth in population; the increasing demand for buildings with comfort conditions; and the growing of indoor occupation time caused by change in the lifestyle [9]. Free cooling coupled with thermal energy storage (TES) is a promising sustainable strategy to meet or rather to minimise the energy consumption by HVAC systems in buildings [10]. Free cooling is the process of storing the natural coolness of the ambient air at night in an appropriate TES unit for subsequent retrieval and use during the daytime using a fan to circulate the air through the system [11]. Compared to sensible heat storage (SHS), latent heat storage (LHS) substances have recently gained a growing interest among the researchers as efficient lightweight TES substancesin the free cooling and heating systems [12], owing to the effectiveness and premium properties of such substances including high density and isothermal performance of the latent heat transfer $[13,14]$. Such materials are known as phase change materials (PCM).

Literature revealed that a number of numerical and experimental studies have been conducted on the free cooling applications in different climates, with the development of numerous designs of PCM-air heat exchanger devices $[15,16]$. Current progress in this technology has been described in many recent review articles. Zeinelabdein et al. [1] highlighted the research development on PCM based free cooling strategy and discussed the major aspects influencing system performance. An extensive investigation on air-PCM-TES systems has been carried out by Iten et al. [17] through detailing passive and active methods and highlighting on their merits 
and limitations. Dardir et al. [18] reported the opportunities and challenges of PCM-to-air heat exchangers (PAHXs) for building free cooling applications concentrating on hot desert climate.

The potential of the free cooling systems incorporating PCM depends principally upon the microclimate conditions, the PCM properties, and the TES unit design [19]. Various PCM microencapsulation techniques including flat plate, cylindrical modules, spherical ball and granules have been utilised considering several heat exchanger configurations such as packed bed, shell with tubes, and integration of air channels between the PCM modules [20, 21].

Turnpenny et al. [22] studied the performance of a cylindrical configuration of PCM with embedded heat pipes under UK summer climate conditions. It has been stated that considerable energy-saving and cost benefits are achievable compared to traditional air conditioning systems. However, further development of the suggested prototype was recommended. Marin et al. [23] have demonstrated that the design of the PCM-air heat exchanger could improve the thermal response of the free cooling system more than utilising a PCM with higher thermal conductivity. This shows the importance and needs for more parametric studies on the TES units design configuration. Based on a numerical study, Darzi et al. [24] reported that the performance of PCM-air heat exchangers is more effective for smaller temperature variation of the indoor air and the PCM liquidus point or for the PCM with a greater latent heat of fusion. Arkar et al. [25] studied the thermal performance of a free cooling system consisting of a cylindrical container filled with sphere encapsulated PCM under the continental climate of Ljubljana, Slovenia. The developed system is able to lessen the size of the mechanical ventilation system and supplying more favourable temperatures and fresh air to the indoors. Panchabikesan et al. [26] stated that the influence of enhancing the PCM heat conductivity on the PCM solidification time relies on the temperature difference between the PCM and the heat transfer fluid (HTF). In the case of insufficient temperature difference, the effect would be minor, and vice versa.

Solgi et al. [27] conducted a parametric study of PCM energy storage performance when coupled with night ventilation in three different Australian climates. It was concluded that in tropical climates, the system performance was non-effective. Nevertheless, in sub-tropical and hot-dry climates, significant energy savings could be realised using optimum PCM transition temperature determined. Osterman et al. [28] carried out a parametric study to assess the thermal performance of PCM energy storage for free cooling in buildings. The measured pressure drops for all tested cases have varied between 2.1 mbar and 13.3 mbar, which implies 
that the impact of the height of the air channels between the PCM panels on the fan energy consumption is insignificant.

132 According to aforementioned studies, application of free cooling in moderate climates has 133 demonstrated a great potential for reducing the building cooling demand and limiting the 134 operation of HVAC systems. On the other hand, According to some studies [1, 18], free cooling 135 is more necessary in hot climates, where the cooling demand is dominant compared to 136 continental, cool and temperate climates. However, there is limited research for hot climates. 137 A TES unit comprising three flat PCM modules arranged in series has been tested inside an environmental chamber by Waqas and Kumar [29, 30]. The capability of the system operation 139 for both cooling and heating in buildings under hot dry and cold dry climate of Islamabad, 140 Pakistan have been examined. It has been indicated that the system is capable of lowering the indoor temperature during the day daytime. However, further research is necessary to augment

142 the cooling potential during severe summer conditions. Muthuvelan et al. [31] investigated the 143 performance of a PCM heat exchanger for free cooling under the hot semi-arid climate of Pune, 144 India. During the discharging period, a temperature drop in the indoor space by $2.5^{\circ} \mathrm{C}$ was recorded. The authors have revealed that the proposed prototype is only efficient in the case of discharging air temperatures higher than the comfort limit by around $5{ }^{\circ} \mathrm{C}$, and that the use of mechanical cooling cannot be dispensed.

Zeinelabdein et al. [32] assessed experimentally the thermal performance of a modular PCMair heat exchanger for free cooling of buildings, where an environmental chamber was used to simulate the hot-dry climate conditions. The findings revealed that narrow air flow channels between the PCM modules could lead to more rapidly charging process, while the period in which the outlet air temperature maintained within the comfort range during the discharging phase is slightly affected by the arrangement of the PCM modules. Accordingly, opptimisation of the TES unit is recommended by the authors to boost the charging process when ambient air temperatures at night are not low enough to release a sufficient amount of heat from the PCM.

156 Based on a feasibility study on a year-round operation of free cooling systems in different 157 climates, Panchabikesan et al. [33] reported that the complete solidification of PCM through free cooling technology in hot dry and composite climates is a challenge. Accordingly, various enhancement techniques to the TES system should be considered to increase cooling efficiency. It can be drawn from the literature that the performance of the free cooling systems requires more improvements in order to achieve sufficient cooling storage capacity, particularly during summer of arid regions; since the ambient temperature is relatively high, the charging period 
163 is limited, and the daytime cooling demand is significant. Furthermore, carrying out comprehensive parametric studies on different PCM-air heat exchanger geometries and air flow rate optimisation are still required, as this influences the solidification and melting phases.

166 In the case of PCM modelling, several methods have been adduced in the literature to solve the 167 phase change process, based on theoretical and experimental studies [13, 34]. The most 168 commonly applied numerical methods are the enthalpy formulation $[35,36]$ and the effective 169 heat capacity method [37, 38]. These two methods have the benefits of permitting one 170 formulation of the heat equation to be used for the whole domain and of avoiding solving the melting front position [39]. Iten et al. [40] stated that both methods can be used to predict the PCM temperature and air temperature of a TES system. The enthalpy method was the most appropriate approach for modelling pure PCMs (a quasi-horizontal curve for the transition phase).On the other hand, the most available PCMs are compound substances with a transition temperature range, in such cases, the phase transition can be accurately simulated through the effective heat capacity method. The authors have also indicated that both methods have presented similar results for predicting temperatures of the HTF, showing well agreements with the experimental data. Zhang et al. [41] reported that results provided by the enthalpy method could be enhanced with proper definition and selection of a specific phase transition temperature range concerning the PCM substance investigated. Computional fluid dynemics (CFD) has widely been considered as a powerful tool in the literature for computing the phase 182 transition process of latent thermal energy systems [42]. CFD utilises an enthalpy-porosity 183 formulation method to resolve the PCM transformation processes [43, 44]. Recent studies [45, 184 46] have proven the proficiency of employing solidification and melting model available in ANSYS Fluent software by presenting a good agreement with the experimental results. The objective of this study is to evaluate the thermal performance of a proposed free cooling system through studying the impact of the TES geometrical configuration, air flow rate, and operating temperature on the solidification and melting behaviour of the PCM.

189 The widely utilised powerful software ANSYS Fluent has been employed for this analysis. One 190 of the essential advantages of the CFD simulation is allowing system optimisation through 191 computing and analysing data which are difficult to be attained from the laboratory experiments 192 such as determination of liquid fraction on a PCM domain and temperature distribution inside 193 a sealed PCM container. A High-Performance Computing (HPC) service was utilised, which 194 permits a large-scale computation and use of more advanced settings for mesh refinement and 
195 time-step reduction towards boosting the precision of the results, compared to a standard 196 computer.

197 The outcomes of this study would be advantageous for producing an optimum design for 198 modular PCM-air heat exchangers, applicable for commercialisation and implementation in 199 buildings based on the parametric study of the TES geometrical configuration and the operating 200 conditions. The current study will add knowledge to the literature database, due to the 201 scarceness of such work based on the PCM energy storage for free cooling targeting the hot202 arid climate of Khartoum and regions with similar climate conditions. 


\section{Targeted location and climate conditions}

204 In this study, Khartoum (the capital of Sudan) has been considered as a location exemplifying

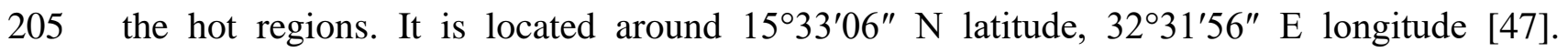

206 According to the Köppen-Geiger climate classification, Khartoum is located in a tropical and 207 subtropical desert climate zone. It is one of the hottest cities in the world and can be classified 208 as a hot arid with dry winter (BWh), which represents the case for most of the middle East 209 countries [48]. Khartoum features a long dry season covering October to June, and a wet season 210 from July to September [47].

211 The monthly outdoor temperature and the diurnal average temperature variation for summer 212 and transitional months (March-October) in Khartoum are demonstrated in Figure 1 (a) and 213 (b), respectively. These data are the average of a 30 years record obtained from the Khartoum 214 airport meteorological station [49].

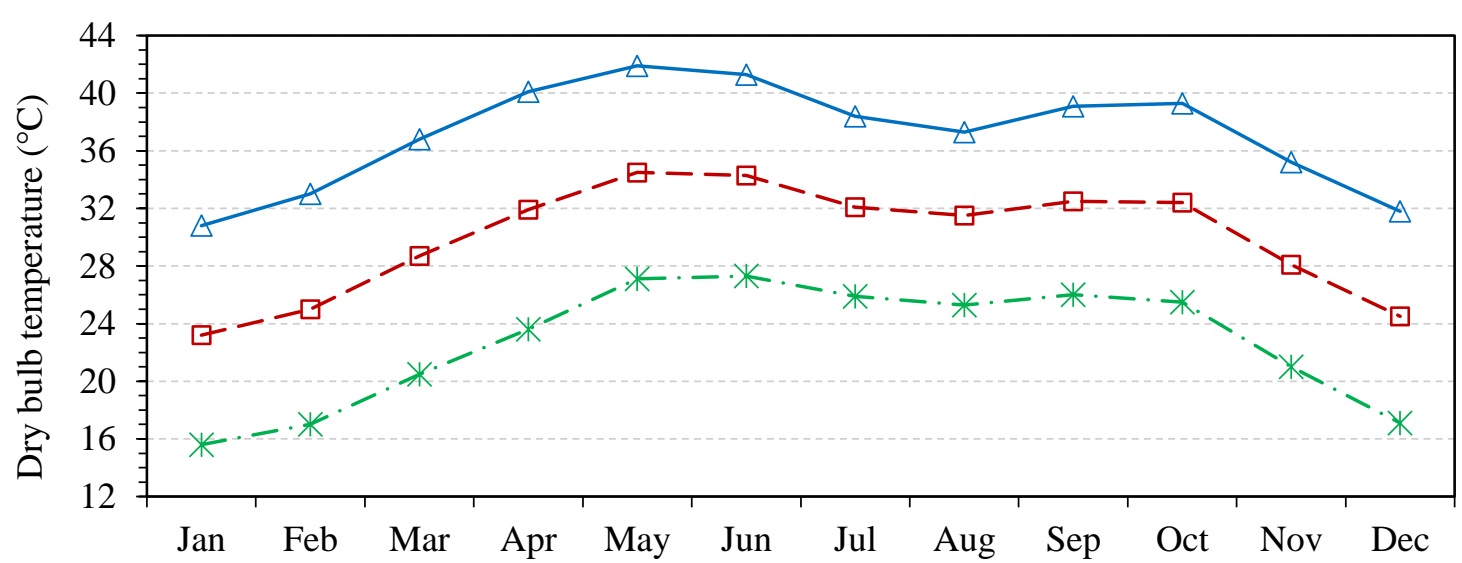
(a) $\triangle$ Maximum Temp. $\quad-\because-$ Average temp. $\quad-*$ - Minimum temp.

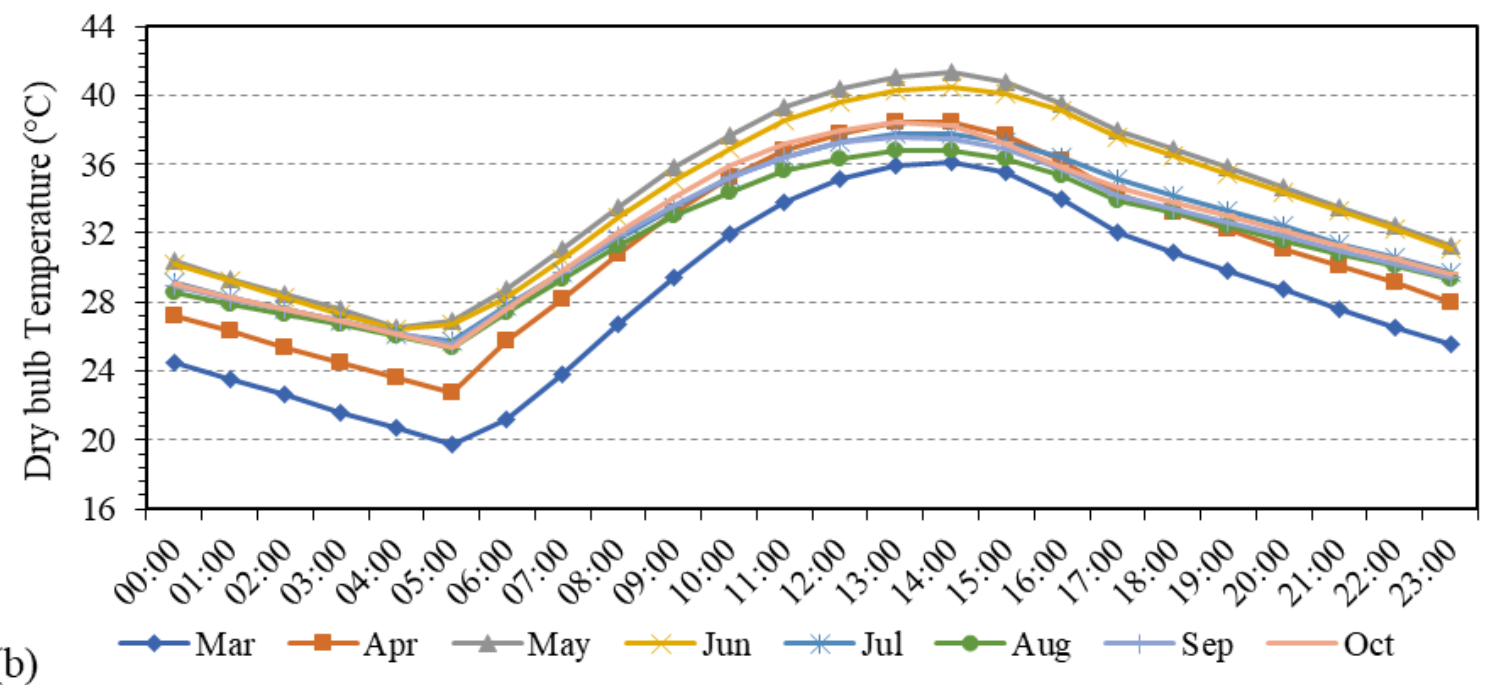

217 Figure 1: Dry-bulb temperature data for the site of Khartoum; (a) Monthly average temperature and,

218 (b) diurnal average temperature at hourly scale for summer and transitional months [49]. 
219 It is clear from Figure 1 that Khartoum climate features an extremely hot summer (May220 September), with average daytime temperatures customarily overdo $40^{\circ} \mathrm{C}$ during peak months 221 (May-June) and is rarely above $44^{\circ} \mathrm{C}$. Conversely, winter (November-February) is 222 characterised by relatively cool nights with temperatures just above $16^{\circ} \mathrm{C}$ and warm daytime 223 conditions, while March and October are considered transitional months. It can be noted that 224 the diurnal temperature variation exceeds $12^{\circ} \mathrm{C}$ throughout the year, indicating high 225 applicability for free cooling in Khartoum and regions with similar climate conditions 226 according to the literature recommendations [11, 50].

227 Figure 1 (b) clarifies that the minimum outdoor temperature is low enough to allow PCM 228 charging and hence, maintaining the daytime thermal comfort level if sufficient energy storage 229 capacity is allocated. However, a lower nocturnal free cooling system efficiency is expected 230 during the peak summer months, when the temperature may not be low enough and the 231 charging period is limited. Thus, it is crucial to understand how the free cooling system 232 performs in such climate conditions.

233 In the present study, the investigated period covers both summer and transitional months 234 (March-October) where there is a serious need for cooling. Besides, the inlet air temperatures 235 tested were based on the weather data presented in Figure 1. 


\section{TES system design}

238 In free cooling applications, the PCM should be carefully chosen to ensure that the phase

239 change temperature suits the diurnal temperature variation of the summer period of the targeted

240 location where most cooling load exists; maintains the outlet air temperature within the comfort

241 zone during the discharging period; and enables fast solidification during the charging period

242 [51]. Accordingly, the paraffin RT28HC produced by Rubitherm was selected for this study. It

243 possesses a melting/solidification temperature range $\left(27-29{ }^{\circ} \mathrm{C}\right)$ which is suitable for the

244 considered climate; high heat of fusion; and the common merits of paraffin substances such as

245 the congruent melting and non-corrosiveness. Thermo-physical properties of the adopted PCM

246 are given in Table 1, and the partial enthalpy distribution is shown in Figure 2.

247 Table 1: RT28HC PCM properties [52].

\begin{tabular}{lllll}
\hline $\begin{array}{l}\text { Phase change } \\
\text { temperature }\end{array}$ & $\begin{array}{l}\text { Heat storage } \\
\text { capacity }\end{array}$ & $\begin{array}{l}\text { Specific heat } \\
\text { capacity }\end{array}$ & $\begin{array}{l}\text { Heat } \\
\text { conductivity }\end{array}$ & $\begin{array}{l}\text { Density } \\
\text { (Liquid-Solid) }\end{array}$ \\
\hline $27-29{ }^{\circ} \mathrm{C}$ & $250 \mathrm{~kJ} / \mathrm{kg} \pm 7.5 \%$ & $2 \mathrm{~kJ} / \mathrm{kg} \mathrm{K}$ & $0.2 \mathrm{~W} / \mathrm{m} \mathrm{K}$ & $0.77-0.88 \mathrm{~kg} / \mathrm{l}$ \\
\hline
\end{tabular}

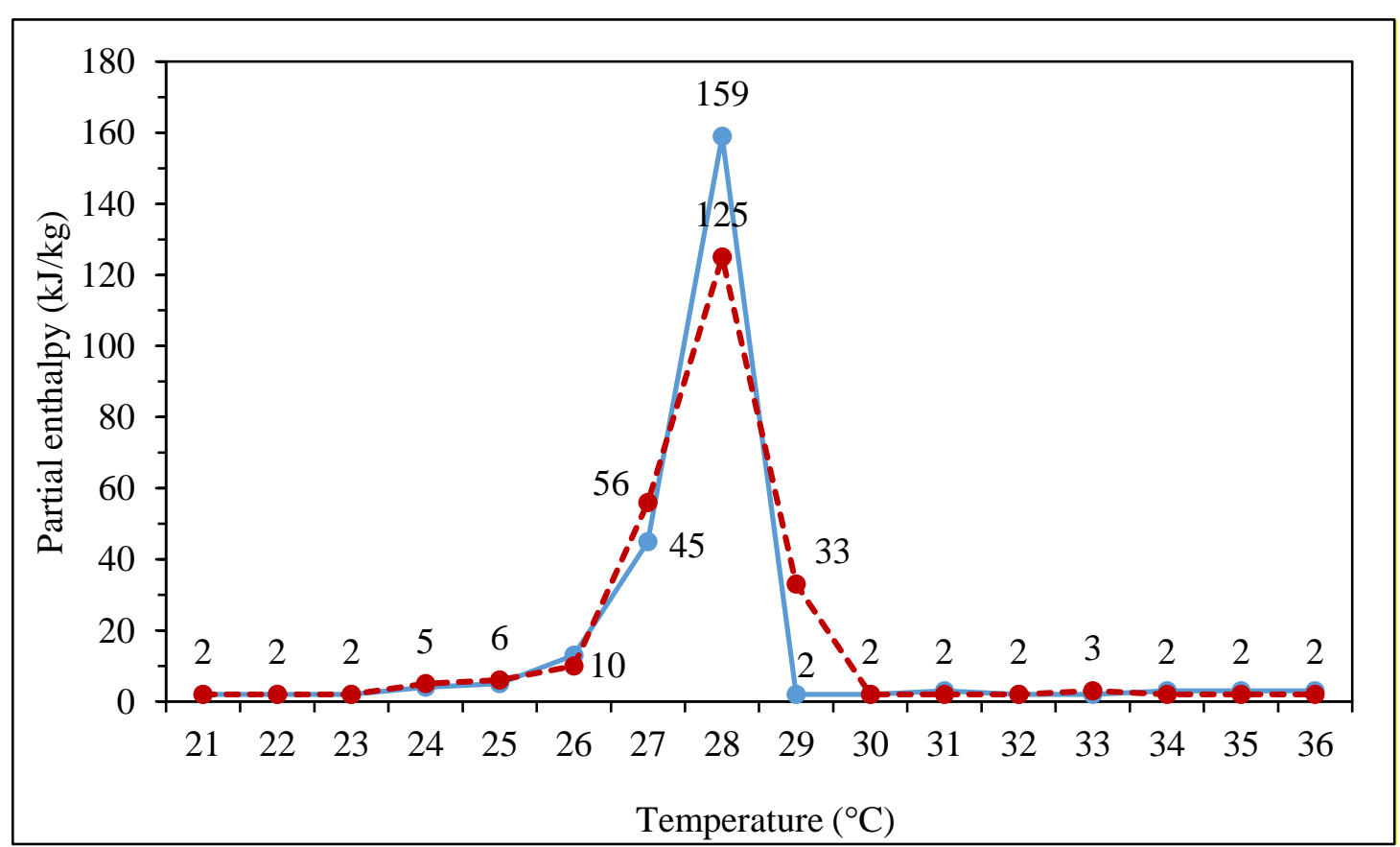

Figure 2: Thermal mass capacity of the RT28HC PCM [52].

250 The TES geometrical configuration was sized based on the PCM specifications given in Table

2511 and the building cooling load estimated for a typical domestic building in the hot-arid climate

252 of Khartoum, Sudan [53]. The system was intended to be used in a room of floor area of $16 \mathrm{~m}^{2}$

253 and is assumed to be thermally enhanced with insulated roof and walls. The TES capacity was

254 approximated to fulfil the cooling requirement of an average day of the peak summer months 
i.e. May and June. A TES system with a cooling capacity of $286 \mathrm{~W} / \mathrm{m}^{2}$ is needed to fulfil the daily cooling load of the room. The required mass of the PCM was obtained using equation (1). It is noteworthy mentioning that PCMs particularly those of organic compounds usually show a rather slow thermal response due to their relatively low thermal conductivity. Therefore, the charging performance of the selected storage capacity is expected to be promising in hot climates during mild summers of a larger temperature variation between the PCM and air contrary to the peak summer period where partial solidification is expected. on the other hand, gradual PCM melting is highly required during the long discharging period, so the effect of the low thermal conductivity is less significant.

$$
\text { Required PCM mass }(\mathrm{kg})=\frac{\text { Total cooling load of the discharging hours }(\mathrm{Wh})}{\text { PCM heat storage capacity }(\mathrm{Wh} / \mathrm{kg})}
$$

Moreover, since air is the heat transfer fluid, the surface convective heat transfer coefficient will be very low. Thus, enlarging the surface area per unit volume of the PCM heat exchanger is beneficial to enhance the convective heat flux. Therefore, the flat-plate module configuration was utilised. A module with overall dimensions of $1800 \mathrm{~mm} \times 600 \mathrm{~mm} \times 10 \mathrm{~mm}$ was suggested, as it well suits the installation at the walls and ceiling space of a standard room. It has been found that 8 PCM modules are required to fulfil the required PCM mass and are capable to satisfy an energy storage capacity of $4.6 \mathrm{kWh}$. Aluminium could be used for the encapsulation of the PCM modules due to its high rate of heat conductivity $(202.4 \mathrm{~W} / \mathrm{m} \mathrm{K})$. The basic configuration of the modular PCM-air heat exchanger unit is depicted in Figure 3. It consists of 8 rectangular aluminium containers filled with PCM. The PCM modules are positioned over each other with air passages of space $15 \mathrm{~mm}$, and with each PCM panel having a $10 \mathrm{~mm}$ thickness for the initial base-case. The thickness of the PCM and height of the air channels are varied to optimise the system geometrical configuration. A well-insulated metallic duct with inlet and outlet apertures was proposed to accommodate the PCM modules and to allow the air flow. As the inlet and the outlet apertures have the full width and height of the duct (Figure 3), the behaviour would be approximately identical in any longitudinal section through the duct. Therefore, a 2D CFD model can be tested in ANSYS software to save the computational time. 


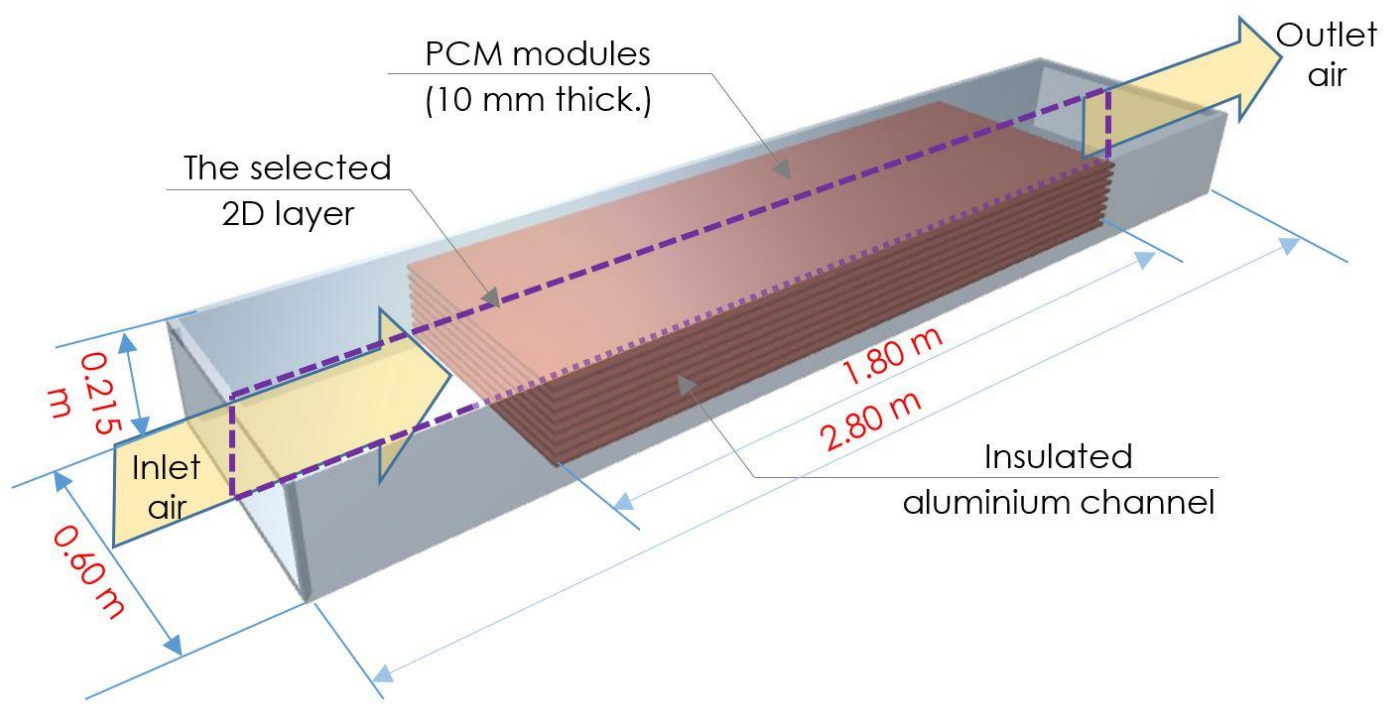

282

283 Figure 3: Configuration of the tested TES unit. 


\section{Methodology}

285 The thermal performance of the TES system was evaluated using CFD modelling. The subsequent assumptions were considered in order to streamline the simulation procedure and shortening the calculations period;

- Both fluids; PCM and air; are incompressible.

- Thermo-physical properties of the HTF are constant and individually specified for each inlet temperature.

- Specific heat, dynamic viscosity and heat conductivity of the PCM are constant and similar for both transition phases, according to the manufacturer data. However, the natural convection as a result of density variation with temperature in the melted PCM was considered according to the piecewise-linear method existing in Fluent.Heat exchange with the surroundings was neglected.

- The volume alteration and PCM movement due to the phase change was neglected as the velocity in the completely melted PCM region is only around $2.6 \times 10-7 \mathrm{~m} / \mathrm{s}$. Consequently, all wall boundaries were set to a non-slip.

In ANSYS Fluent, the Pressure-Based flow equations solver was selected as the HTF is considered incompressible. The assigned models, materials, boundary conditions, and solution settings are discussed below.

\subsection{Models and governing equations}

303 The continuity and the momentum equations are solved for the viscous air flow. The energy conservation equation is solved for the air flow along with that for the PCM zone using the solidification/melting model as follows:

\subsubsection{Flow and Energy models for the HTF}

307 For the proposed ducting system and range of tested air flow velocities, the flow regime was 308 considered turbulent according to the computed Reynolds numbers. The broadly utilised 309 Reynolds-Averaged Navier-Stokes (RANS) equations for fully turbulent air flow modelling in 310 industrial CFD are solved. The realizable $k-\varepsilon$ was accepted as it possesses substantial 311 enhancements over the k- $\varepsilon$ family (standard and RNG models) for several validations of a wide 312 range of flows [54, 55]. Based on the selected models and aforementioned assumptions, the 313 conservation equations solved can be simplified as follows [56, 57]; 
Continuity

$$
\begin{aligned}
& \text { Momentum } \\
& \frac{\partial u_{i}}{\partial t}+\frac{\partial u_{i} u_{j}}{\partial x_{j}}=-\frac{1}{\rho} \frac{\partial p}{\partial x_{i}}+\gamma \frac{\partial^{2} u_{i}}{\partial x_{j} \partial x_{j}}-\frac{\partial \overline{\hat{u}_{l} \dot{u}_{j}}}{\partial x_{j}} \\
& \text { Energy } \\
& \rho C_{p}\left(\frac{\partial T}{\partial t}+\frac{\partial u_{i} T}{\partial x_{i}}\right)=\frac{\partial}{\partial x_{i}}\left(\lambda_{e f f} \frac{\partial T}{\partial x_{i}}\right)+S \\
& (i=1,2),(j=1,2)
\end{aligned}
$$

\section{$315 \quad$ 4.1.2 Solidification/melting model}

316 The solidification/melting model available in ANSYS Fluent was applied. It utilises an

317 enthalpy-porosity formulation method to resolve the PCM transformation processes [43, 44].

318 In this method, the solid-liquid front is not computed explicitly. Instead, a magnitude called 319 liquid fraction associated with each cell in the domain is utilised. The liquid fraction is 320 computed at each iteration based on an energy balance using equations (5)-(9). The liquid-solid 321 mushy zone is regarded as a porous region with porosity corresponding to the liquid fraction, 322 which ranges from 1 for full melting to zero for complete solidification in the cell.

323 The specific enthalpy $(H)$ of a substance is proportional to the sensible heat $(h)$ and the latent 324 heat $(\Delta h)$ based on equations (5)-(7);

$$
\begin{gathered}
H=h+\Delta h \\
h=h_{\text {ref }}+\int_{T_{\text {ref }}}^{T} C_{p} d t \\
\Delta h=\beta L
\end{gathered}
$$

325 The liquid fraction $(\beta)$ can be estimated using equation (8);

$$
\begin{array}{ll}
\beta=0 & \text { if } T<T_{\text {solidus }} \\
\beta=1 & \text { if } T>T_{\text {liquidus }} \\
\beta=\frac{T-T_{\text {solidus }}}{T_{\text {liquidus }}-T_{\text {solidus }}} & \text { if } T_{\text {solidus }}<T<T_{\text {liquidus }}
\end{array}
$$


The energy equation solved for the solidification/melting model can be written as follows;

$$
\rho \frac{\partial H_{i}}{\partial t}=\lambda \frac{\partial T_{i}}{\partial x_{i}}+S
$$

329 In general, heat transfer in a PCM medium is an unsteady-state, non-linear (equations (5)-(7))

330 phenomenon as a result of the movement of the solid-liquid interface, ordinary known as a

331 "moving boundary" problem. This boundary changes with time, based on the speed at which

332 the latent heat is absorbed or released at the boundary. Overall, the current CFD solution does

333 not consider the linear phenomena related to the phase change, including subcooling, phase

334 segregation and hysteresis.

335

336

337

338

339

340

341

342

\subsection{Boundary conditions and solution methods}

The assigned boundary conditions and locations of the observed points are shown in Figure 4. The boundary condition for the inlet was set as velocity inlet and for the outlet was pressure outlet. The interface between the PCM zone and the HTF zone was defined as a coupled wall. The outer container walls were set to adiabatic.

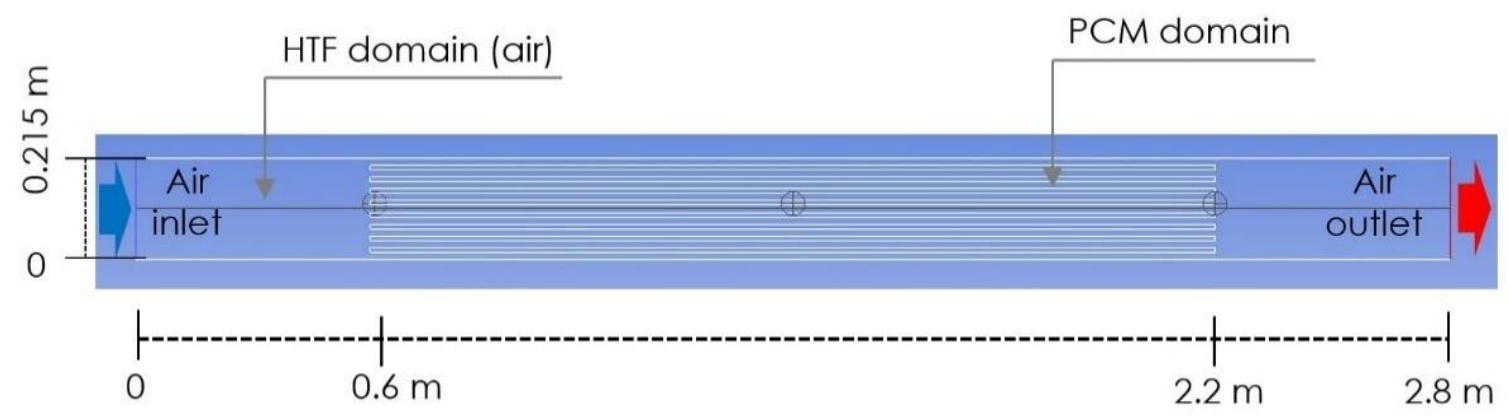

Figure 4: Assigned boundary conditions.

The coupled algorithm was applied for the pressure-velocity coupling. For the spatial discretisation, the second-order upwind scheme was selected for solving the momentum, the energy, and the transient formulation. Presto scheme was considered for the pressure correction equation. The under-relaxation factors were remained default. The hybrid initialisation method was applied. The highest iteration per time-step was 20, which is sufficient to satisfy the convergence criteria of the default residual tolerances of $10^{-3}$ for continuity, $x$ and y velocities, and turbulence $\mathrm{k}$ - equations, and $10^{-6}$ for energy equation. 


\subsection{Initial settings and tests conditions}

352 In the charging process, the PCM was assumed totally melted at a temperature of $32{ }^{\circ} \mathrm{C}$ higher 353 than its liquidus point by $3 \mathrm{~K}$. Cold air of a specific temperature and flow rate is passed through 354 the system resulting in heat absorption from the PCM, which commences freezing 355 progressively. A constant inlet air temperature average of the entire charging period has been 356 used in each test. This could be a suitable assumption, since the prevailing charging period is very short, and the temperatures are close.

358 In the discharging process, the PCM was initially totally solid at a temperature of $24{ }^{\circ} \mathrm{C}$ lower than the PCM solidus point by $3 \mathrm{~K}$. The circulated hot air loses heat to the cooler PCM and the

360 PCM begins to melt gradually. The inlet air temperature was remained steady throughout the whole discharging period since buildings with high thermal mass ordinarily experienced small indoor temperature swing.

363 In this study, the base case geometry has a $10 \mathrm{~mm}$ thickness of the PCM module and a $15 \mathrm{~mm}$ 364 air channel height. Time and mesh independence studies were initially conducted for the base case model to ensure the solution accuracy and calculation time reduction. The numerical model has been verified with a published experimental study performed by the authors [32].

367 The conducted parametric study and the associated test conditions for both charging and discharging processes are explained below

\subsubsection{Inlet air temperature}

370 For PCM charging, selection of inlet air temperatures was according to the prevalent ambient conditions during peak and moderate summer months in Khartoum as presented in Figure 1.

372 Five inlet air temperatures have been examined 21 and $23^{\circ} \mathrm{C}$ for simulating the charging 373 process during moderate summer months (March and April), and 25, 26, and $27^{\circ} \mathrm{C}$ for the representation of hot summer months (May-October).

375 For the discharging phase, circulation of indoor air through the PCM modules is in preference to the hotter ambient air. Therefore, three inlet air temperatures have been tested; 34,36 and

$37738{ }^{\circ} \mathrm{C}$; which could represent the indoor air temperatures for a room with various insulation 378 levels, or may represent indoor temperatures at different periods during summer of the hot arid 379 climate (Figure 1). The examined inlet temperatures for both transition phases are summarised 380 in Table 2. 


\begin{tabular}{lll} 
& Inlet air temp. $\left({ }^{\circ} \mathbf{C}\right)$ & Air flow rate $(\mathbf{L} / \mathbf{s})$ \\
\hline Charging test & $21,23,25,26$, and 27 & 213 \\
Discharging test & 34,36, and 38 & 53 \\
\hline
\end{tabular}

$382 \quad$ 4.3.2 Air flow rate

383 To understand the role of the air flow rate on the phase change behaviour of the PCM. Five air

384 flow rates for both phases were tested (Table 3). The air flow rates adopted for the discharging 385 process (13-107 L/s) are recommended for comfort ventilation in typical domestic rooms [58].

386 While for the charging process, air flow rates equivalent to 3-4 times of the discharging flow 387 rate were selected, as these were found appropriate based on previous studies $[59,60]$.

388 Table 3: Tested air flow rates.

\begin{tabular}{lll}
\hline & Air flow rate $(\mathbf{L} / \mathbf{s})$ & Inlet air temp. $\left({ }^{\circ} \mathbf{C}\right)$ \\
\hline Charging test & $107,213,320,427$, and 533 & 23 \\
Discharging test & $13,27,53,80$, and 107 & 36 \\
\hline
\end{tabular}

\subsubsection{TES geometrical configuration}

390 The objective of this study was to optimise the geometrical configuration of the TES system integrated into free cooling systems. Six cases with similar energy storage capacities but varying PCM thicknesses and air channels height were investigated as presented in Table 4.

393 The thermal performance was investigated using inlet temperature of $23{ }^{\circ} \mathrm{C}$ and air flow rate 394 of $213 \mathrm{~L} / \mathrm{s}$ for the charging procedure; and inlet temperature of $36{ }^{\circ} \mathrm{C}$ and air flow rate of 53 $395 \mathrm{~L} / \mathrm{s}$ for the discharging procedure.

396 Table 4: Geometrical details of the tested cases.

\begin{tabular}{lllll}
\hline Case & $\begin{array}{l}\text { PCM thickness } \\
(\mathbf{m m})\end{array}$ & $\begin{array}{l}\text { Air channel } \\
\text { height }(\mathbf{m m})\end{array}$ & $\begin{array}{l}\text { Number of } \\
\text { PCM modules }\end{array}$ & $\begin{array}{l}\text { Main duct } \\
\text { height }(\mathbf{m})\end{array}$ \\
\hline Case 1 & & 5 & & 0.165 \\
Case 2 & 5 & 10 & 16 & 0.25 \\
Case 3 & & 15 & & 0.335 \\
\hline Case 4 & & 10 & & 0.17 \\
Case 5 & 10 & 15 & 8 & 0.215 \\
Case 6 & & 25 & & 0.305 \\
\hline
\end{tabular}

397 In order to enhance the accuracy level of the results under current system design, operating 398 conditions and modelling settings, a high-performance computing (HPC) facility is used to run 
where; $\dot{V}$ is the air volume flow rate, and $\eta_{f a n}$ is the fan efficiency which has been assumed at

4130.55 according to Franconi et al. [62].

414 The total energy consumption $\left(E_{\mathrm{fan}}\right)$ in the current system involves the fan operation during 415

\section{$417 \quad 4.4 \quad$ Independence tests}

418 For an unsteady-state simulation, initial tests were carried out for the base model to guarantee 419 that the solution is independent of time and mesh size prior to the initiation of the major study. 420 This step is essential to increase the solution accuracy and reducing the calculation time. 


\subsubsection{Time independence study}

422 For the current analysis, three time-steps $0.05,0.1$, and $0.2 \mathrm{~s}$ were tested. The variation in the 423 PCM liquid fraction under the considered time-steps is presented in Figure 5 (a) and (b) for the 424 charging and discharging phases, respectively. According to Figure 5a, it is clear that the PCM 425 liquid fraction computed using time-steps of $0.05 \mathrm{~s}$ and $0.1 \mathrm{~s}$ is nearly identical throughout the 426 entire charging process. However, a variation is observed in the case of $0.2 \mathrm{~s}$ time-step, which 427 led to a delay in the PCM solidification by around 3.5\% compared to that obtained with $0.05 \mathrm{~s}$ 428 time-step. In contrast, in the case of discharging simulation, Figure $5 \mathrm{~b}$ shows that the simulation 429 was independent of time for the first 3 hours, after which, a variation of the PCM liquid fraction 430 computed by a time-step of $0.2 \mathrm{~s}$ is appeared for the rest of the simulation time, where the PCM 431 melting time was quicker by around $3.7 \%$ compared to the $0.05 \mathrm{~s}$ time-step.

432 As reported in the literature [56], for a transient state simulation, the accuracy of the results 433 increases at the smaller time-step. Therefore, in order to obtain high accuracy with reasonable 434 computational time, a time-step of $0.1 \mathrm{~s}$ was adopted for all simulation cases of the basic model. 435 It is worth mentioning that the smallest time-step (0.05 s) was used when the geometry has 436 been changed.

437
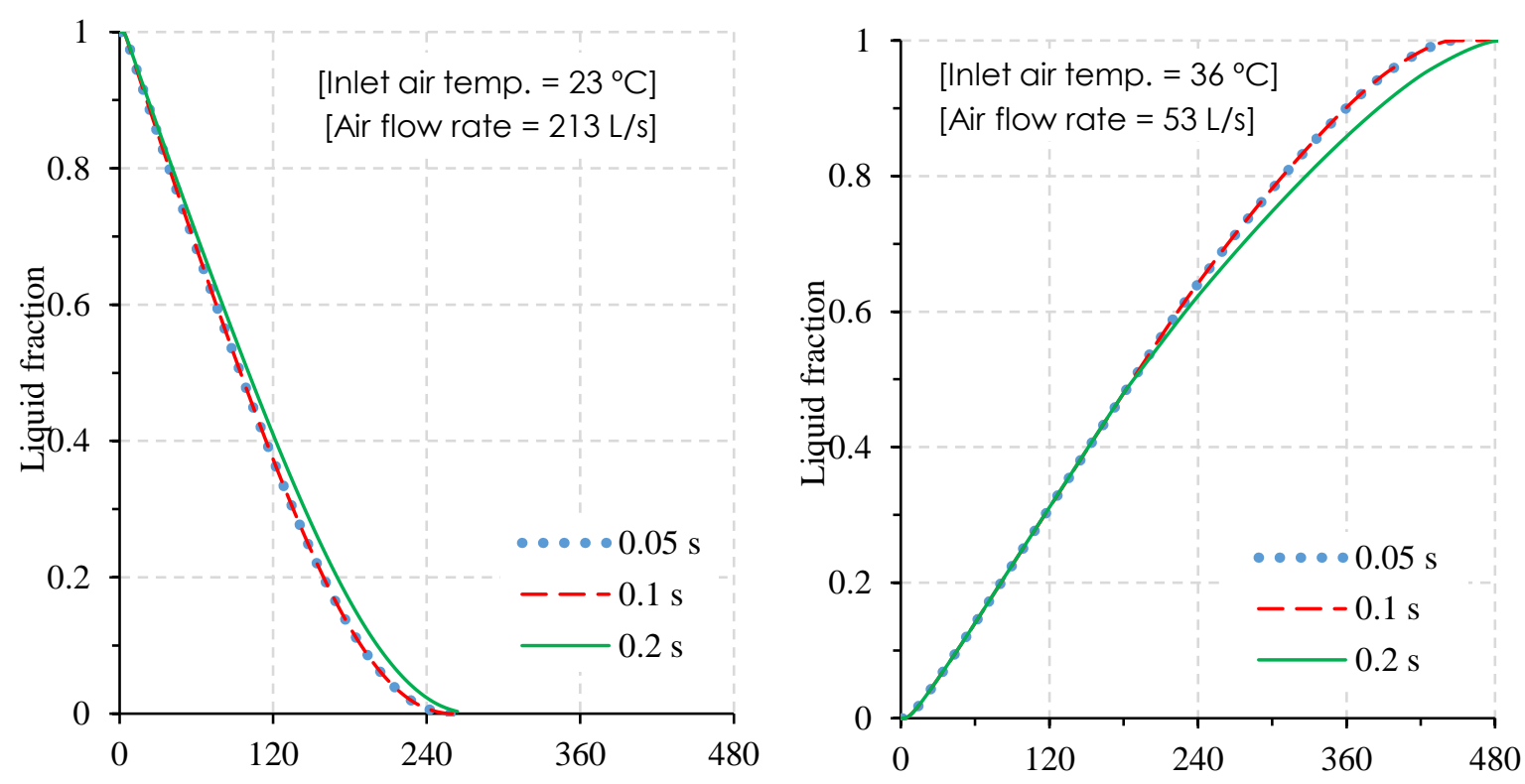

(a)

Time (min)

(b)

Time (min)

439 Figure 5: PCM liquid fraction at different time-steps during (a) charging and (b) discharging process. 
441 The simulation quality depends significantly on the mesh size applied to the geometry. An 442 independence test was carried out for a preliminary case under three different grid densities as 443 detailed in Table 5 in order to select the optimum grid. The tested sizes of the mesh edge are 444 in the range recommended for natural ventilation applications [64]. Figure 6 compares the PCM 445 mean liquid fraction during full charging process for the three tested grids. It is clear that the 446 PCM liquid fraction in all cases follows a similar trend throughout the whole simulation and 447 the variations are generally small with a maximum of $1.9 \%$. Therefore, an adequate mesh of $448 \quad 2.5 \mathrm{~mm}$ edge size (Grid B) was adopted for the entire simulation cases.

449 Table 5: Mesh information.

\begin{tabular}{lll}
\hline & Edge size & Total number of cells \\
\hline Grid A & $1.0 \mathrm{~mm}$ & 192788 \\
Grid B & $2.5 \mathrm{~mm}$ & 70078 \\
Grid C & $3.0 \mathrm{~mm}$ & 48197 \\
\hline
\end{tabular}

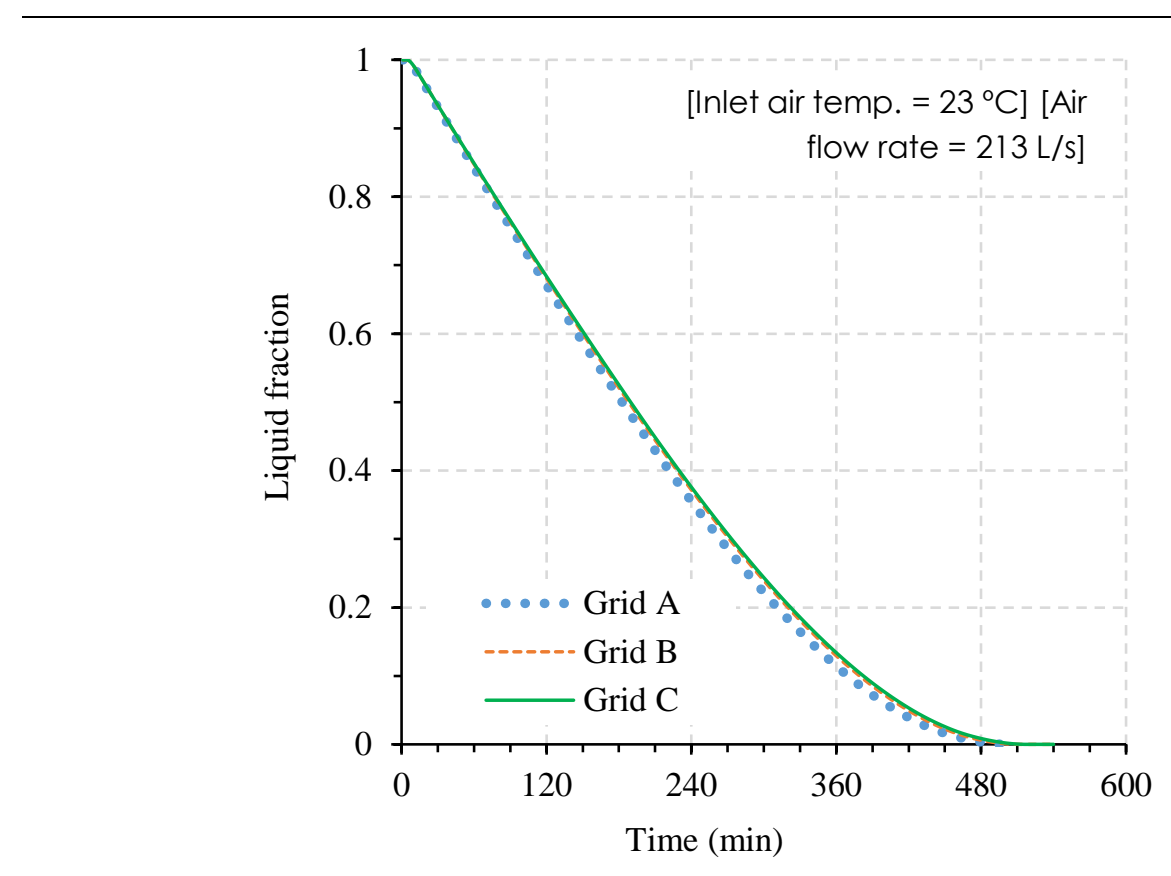




\section{Validation}

453 To validate the CFD model, a comparison between the results obtained through the CFD 454 simulation and experimental results published by the authors in [32] has been carried out. A $4552 \mathrm{D}$ geometrical model (Figure 7a), comparable to the experimental apparatus which comprises 456 two sets of RT28HC PCM modules (Figure 7b) was created, meshed, and tested in ANSYS 457 Fluent for thermal performance analysis. The boundary conditions were set similar to the 458 experimental setup. The adopted assumptions and settings of the calculation models, governing 459 equations, and solutions methods were similar to those described in section 4. The PCM 460 average temperature was estimated at two locations along the channel; PCM_I and PCM_II for 461 the front and the rear sets of PCM modules, respectively (Figure 7a). The adopted measurement

462 locations in the model were in correspondence with those in the experiments.

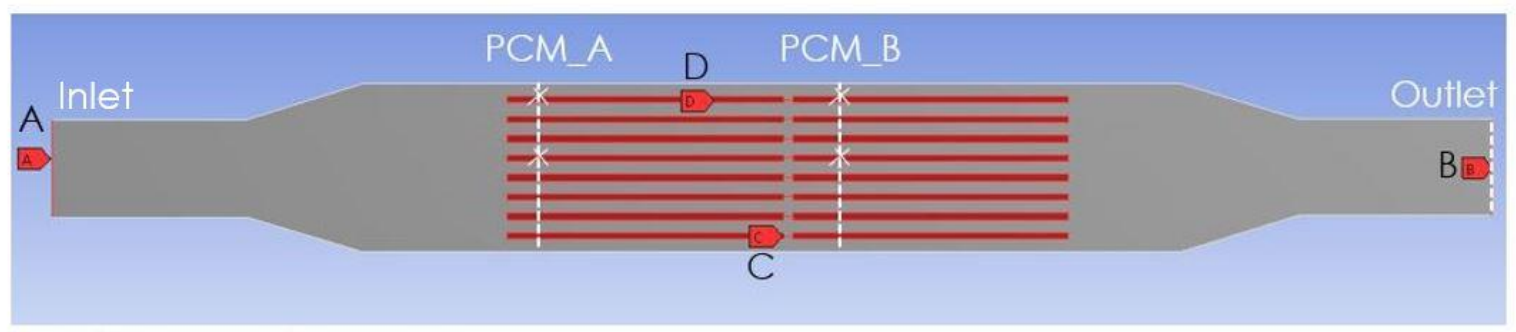

(a)
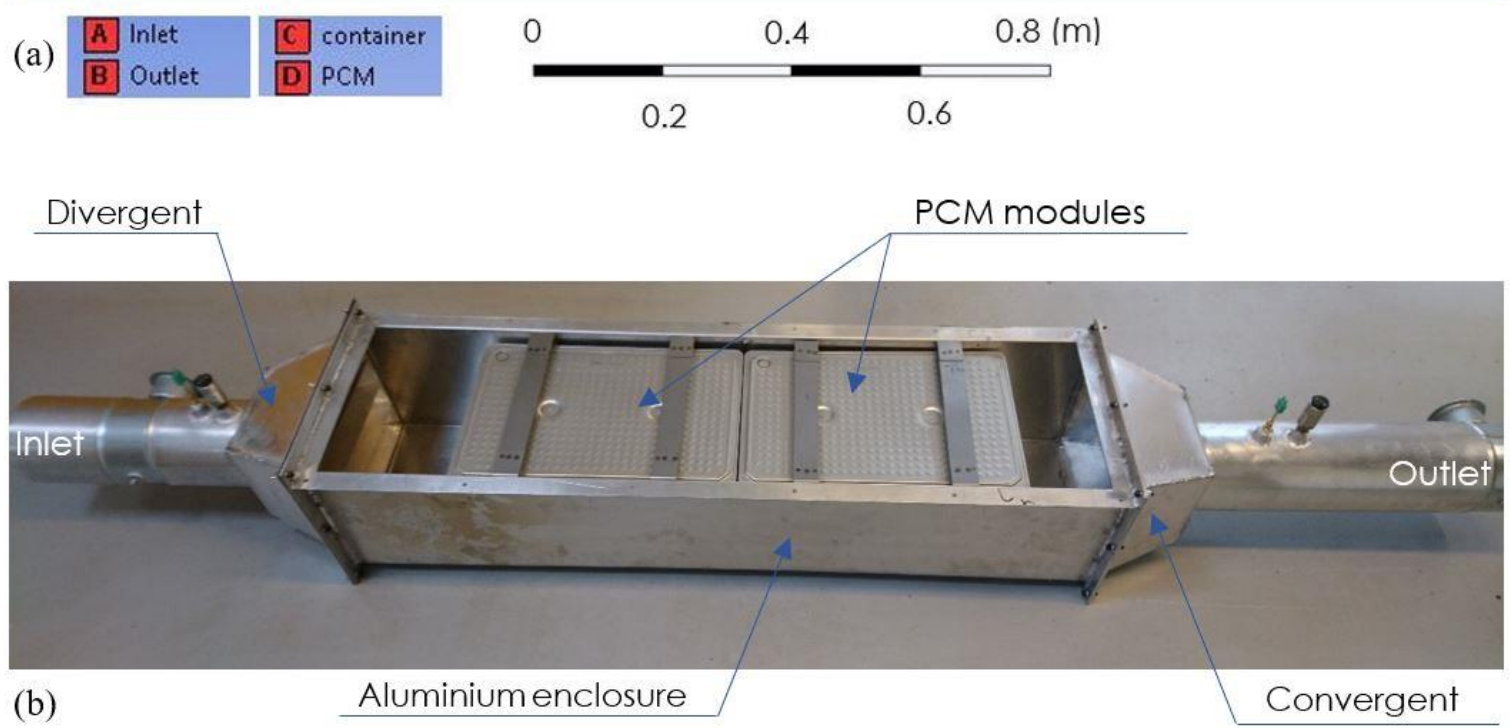

463

Figure 7: (a) Simulated model in ANSYS software. (b) the laboratory tested TES unit. 
465 The validation was performed for the charging and discharging phases as demonstrated in 466 Figure 8.

467 From Figure 8a, the three successive phases that the PCM passes through during the charging period (initial sensible cooling, phase change, and latter sensible cooling) are clear in both modelling and experimental data. During initial sensible cooling, the drop of the PCM temperature was very sharp from the initial temperature $\left(34^{\circ} \mathrm{C}\right)$ to the liquidus temperature (28 ${ }^{\circ} \mathrm{C}$ ), with a lower severity in the case of the experiment than the simulation. One of the reasons could be the inlet temperature variation at the starting of the charging process. Unlike the numerical analysis where the inlet temperature was constant all the time, the air drawn from the environmental chamber had a slightly higher temperature, which required a few minutes to stabilise at the target temperature. Moreover, the variation at some point prior to the phase alteration process was due to supercooling of the experimentally tested PCM, owing to the nature of the paraffin. During the transition phase, where the PCM temperature declined gradually from $28^{\circ} \mathrm{C}$ to $27^{\circ} \mathrm{C}$, it can be observed that the measured and predicted temperatures at the considered locations have shown a good agreement throughout the entire phase. Subsequently, the sensible cooling was quite rapid in the simulation and gradual in the experiment. This is likely to be caused by the presence of some latent heat in the experimentally investigated PCM.

For the discharging process, it is evident from Figure 8b that the PCM in both cases passes through an initial sensible heating phase, followed by a phase change stage, and latter sensible heating ahead of reaching the steady-state conditions. The initial sensible heating took longer time in the case of the experiment than the simulation, owing to the slightly lower inlet air temperature initially before reaching the target temperature after a certain time. During the phase change, the PCM temperature obtained through the numerical and experimental analysis were in a good agreement most of the time. Following the phase change process, the increase of PCM temperature was sharp in the case of numerical analysis. However, this is not the case for experiments where the temperature increase was gradual and smooth due to the presence of some latent heat at temperatures higher and lower than the dominant range.

493 To sum up, temperatures obtained numerically and experimentally have exhibited a 494 comparable trend and were in a good agreement. The temperature profile was very smooth in the experimental measurements and linearly for the modelling results, due to the variation of thermo-physical properties with the temperature, which met by fixed values used in the CFD modelling for both air and PCM properties, in addition to the PCM solidus and liqudius 
498 temperatures which have been considered as single values based on the manufacturer data,.

499 Another reason for the discrepancy could likely be the uncertainty of the experimental 500 measurements, which has been estimated at $\pm 1.12 \%$ [32]. Overall, successful validation of the 501 results was completed under both charging and discharging operating conditions. Hence, it can 502 be stated that the CFD model adopted in this research could be utilised for the phase change 503 simulation.
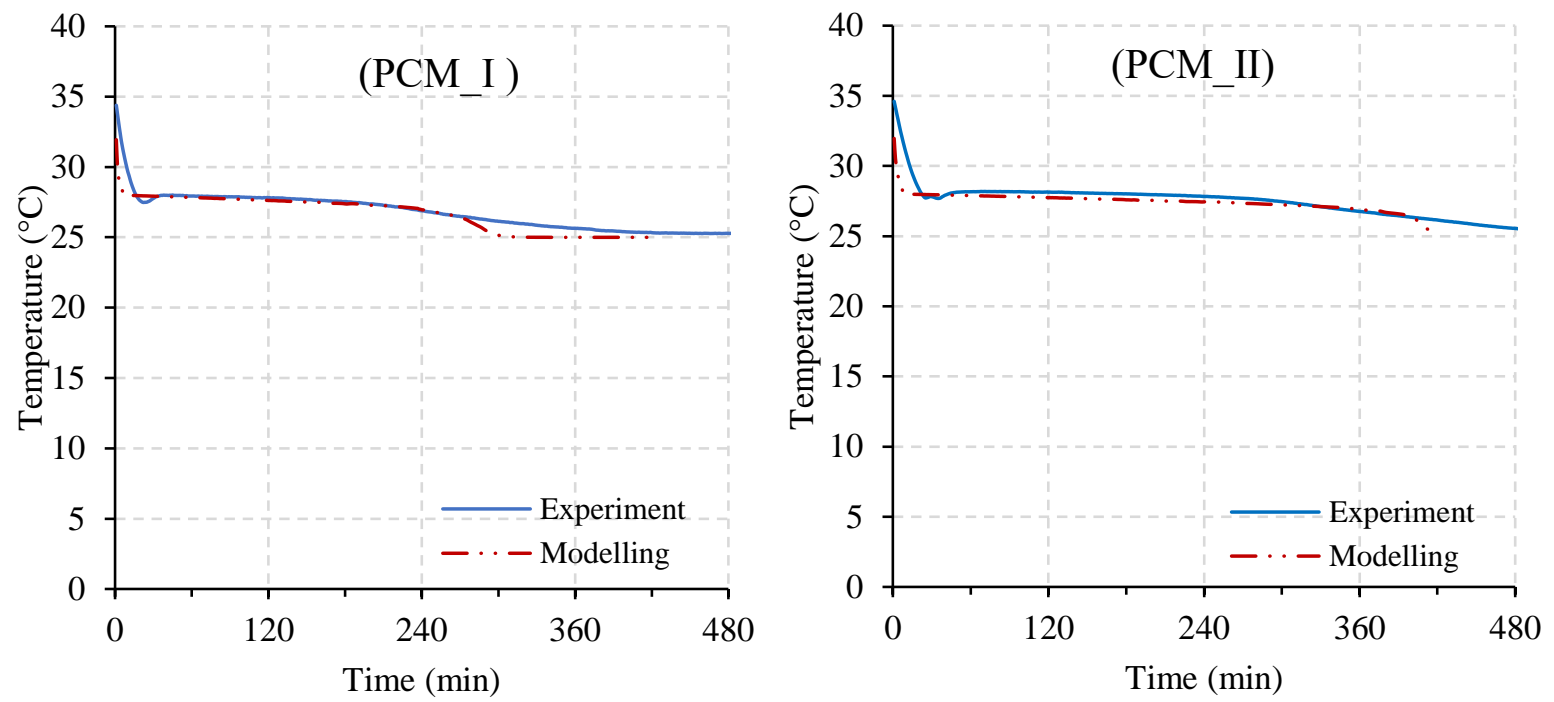

(a)
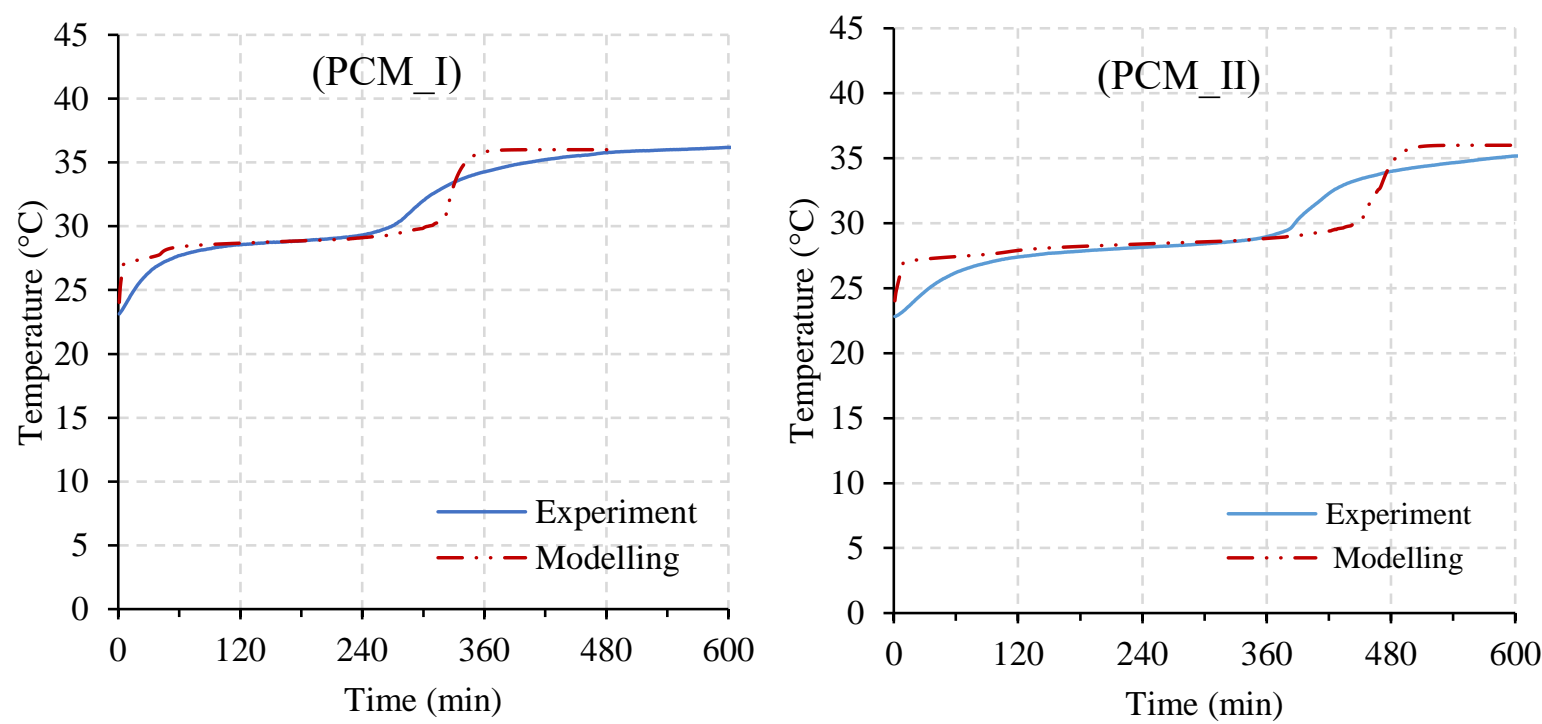

(b)

508 Figure 8: A comparison between numerical and experimental PCM temperatures for (a) charging, and 509 (b) discharging simulations. 


\section{Results and discussion}

511 For the adopted tests, the discussed results involve average liquid fraction and temperature of

512 the PCM; mean outlet air temperature; solidification and melting time; pressure drop through

513 the system, and fan power consumption analysis.

\section{$514 \quad 6.1 \quad$ Influence of inlet air temperature}

$515 \quad$ PCM charging

516 Figure 9 (a) and (b) show the variation in the PCM liquid fraction and the outlet air temperature,

517 respectively, during full charging process for the tested inlet air temperatures. Under the current

518 PCM arrangement and suggested air flow rate of $213 \mathrm{~L} / \mathrm{s}$, Figure 9a shows that a complete

519 PCM solidification can be quickly reached after 5.75 hours when the inlet air is at a temperature

$52021{ }^{\circ} \mathrm{C}$ and could take up to 21.95 hours at a temperature $26{ }^{\circ} \mathrm{C}$. The full solidification was

521 difficult to be obtained when the inlet temperature was $27^{\circ} \mathrm{C}$, even after 24 hours of charging

522 process where the solid PCM fraction reached 59\%. This is attributable to the low temperature

523 difference between the PCM and the air.

524 Results presented in Figure 9b indicated that the outlet air temperature remained within the

525 comfort zone in all cases, apart from the initial 10-30 minutes of the sensible cooling process.

526 The lower the inlet temperature, the lower the outlet temperature would be. Nevertheless, the

527 air flow rate might be too high for direct admission into the indoor space.

528 Table 6 recaps the expected time for getting full PCM solidification under the examined inlet

529 air conditions. It has been found that the change in solidification time with inlet air temperature

530 has a nonlinear relation. As an example, the solidification time extends by around $45 \%$ with a

$5312 \mathrm{~K}$ inlet air temperature increase from $21^{\circ} \mathrm{C}$ to $23^{\circ} \mathrm{C}$ and by around $65 \%$ with the temperature

532 increase from $25^{\circ} \mathrm{C}$ to $26^{\circ} \mathrm{C}$. Figure 10 depicts the contours of liquid fraction and temperature

533 distribution in the PCM area after 4 hours of charging for the tested inlet air temperatures. 


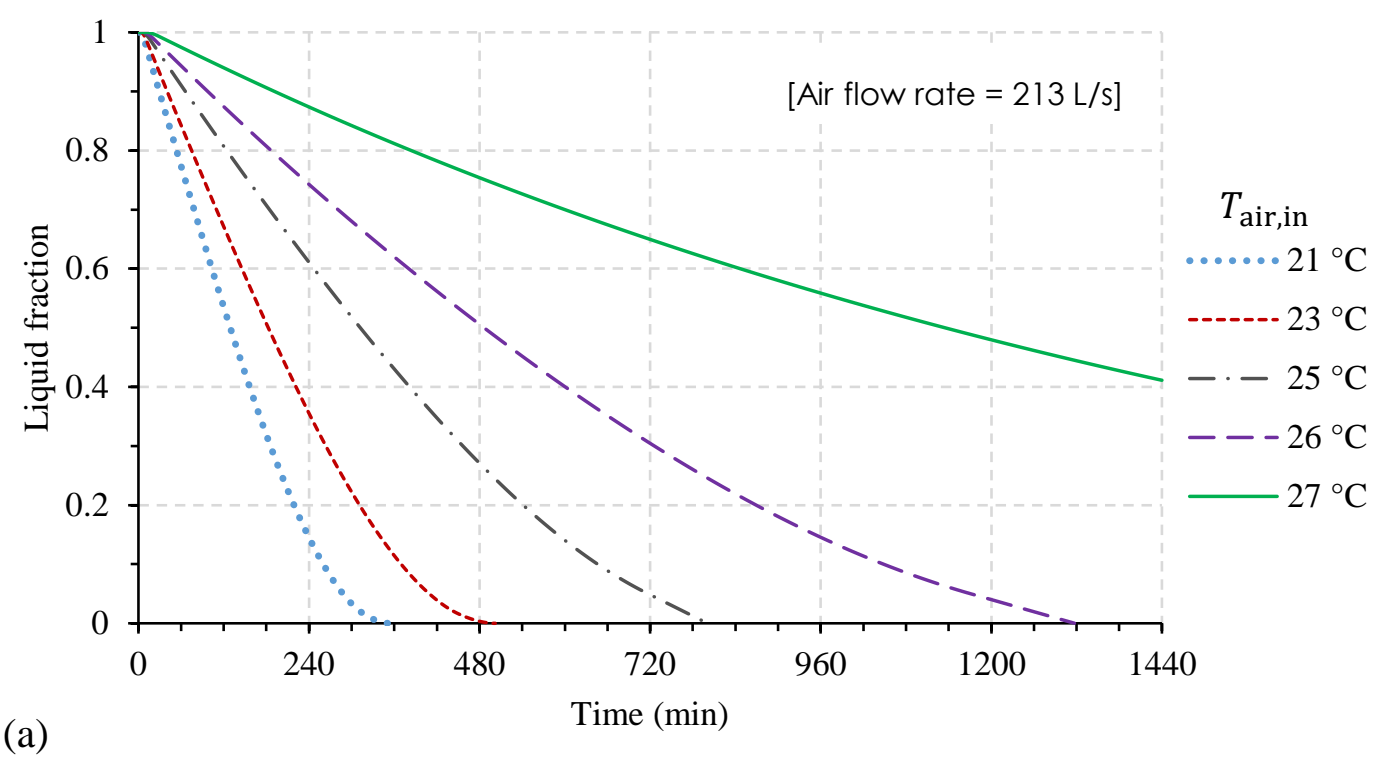

534

(a)

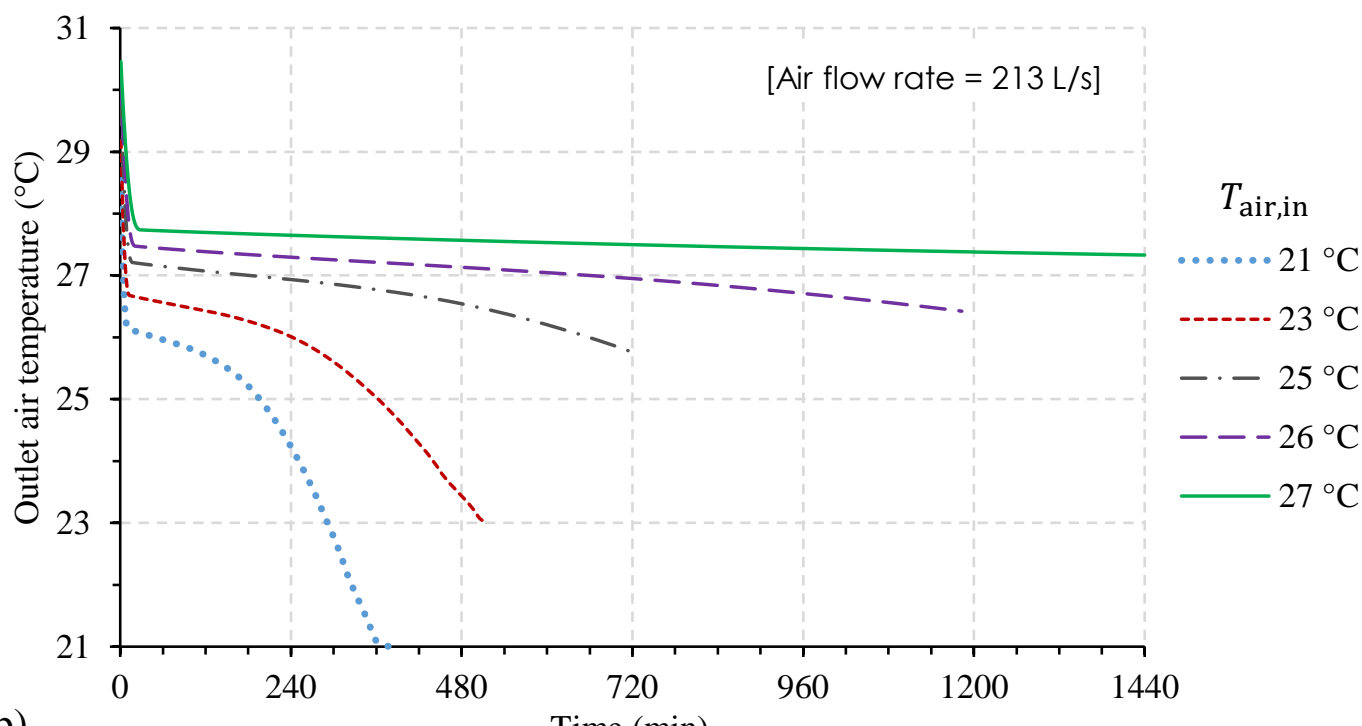

535

(b)

Time (min)

536 Figure 9: Variation of (a) PCM liquid fraction and (b) outlet air temperature for different inlet air 537 temperatures during the charging process.

538 Table 6: Solidification time under tested inlet temperatures at the air flow rate of $213 \mathrm{~L} / \mathrm{s}$.

\begin{tabular}{llllll}
\hline & \multicolumn{5}{l}{ Inlet air temperature } \\
\cline { 2 - 6 } & $\mathbf{2 1}{ }^{\circ} \mathbf{C}$ & $\mathbf{2 3}^{\circ} \mathbf{C}$ & $\mathbf{2 5}^{\circ} \mathbf{C}$ & $\mathbf{2 6}^{\circ} \mathbf{C}$ & $\mathbf{2 7}^{\circ} \mathbf{C}$ \\
\hline Solidification time (hours) & 5.75 & 8.33 & 13.33 & 21.95 & N.A. \\
\hline
\end{tabular}

539 


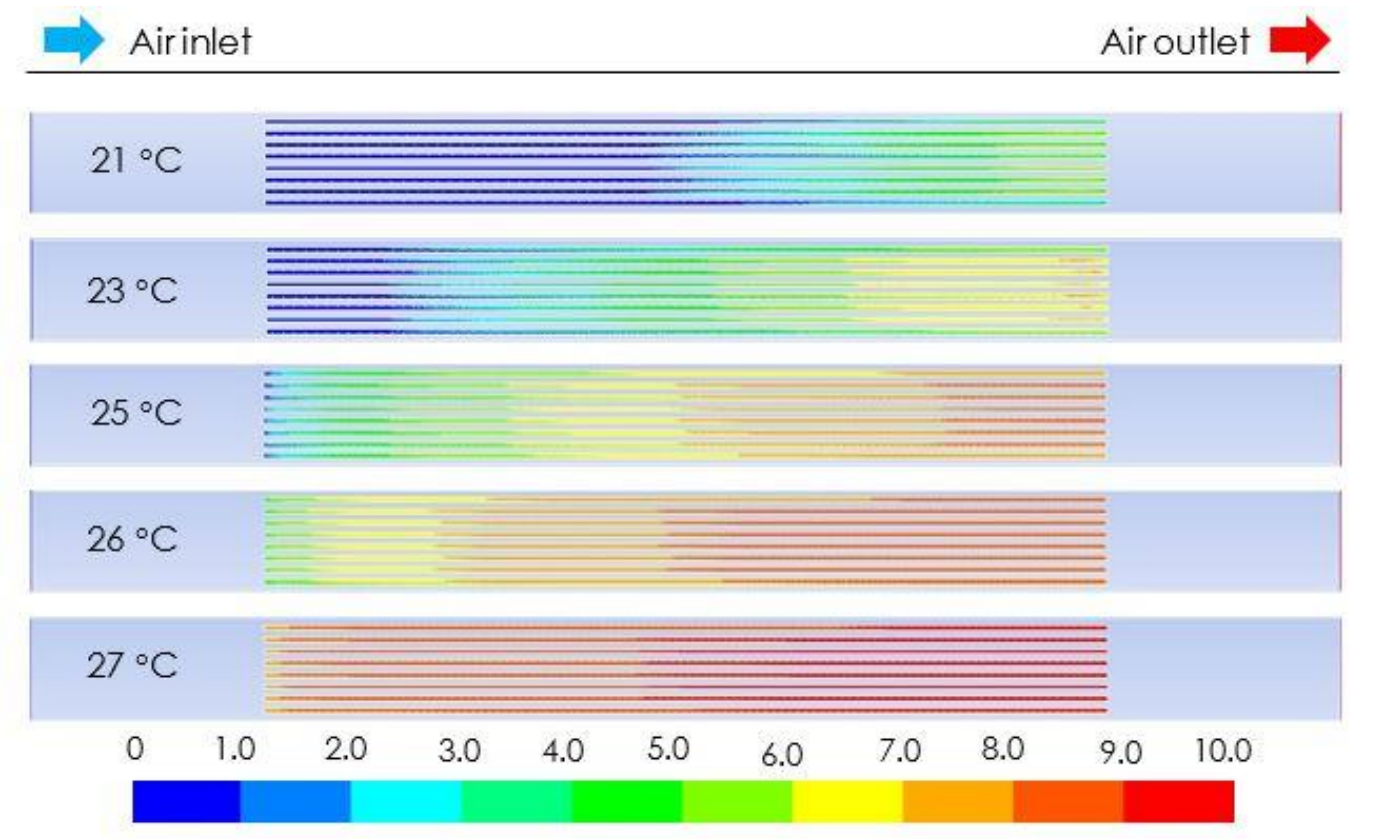

\section{(a) Liquid fraction}
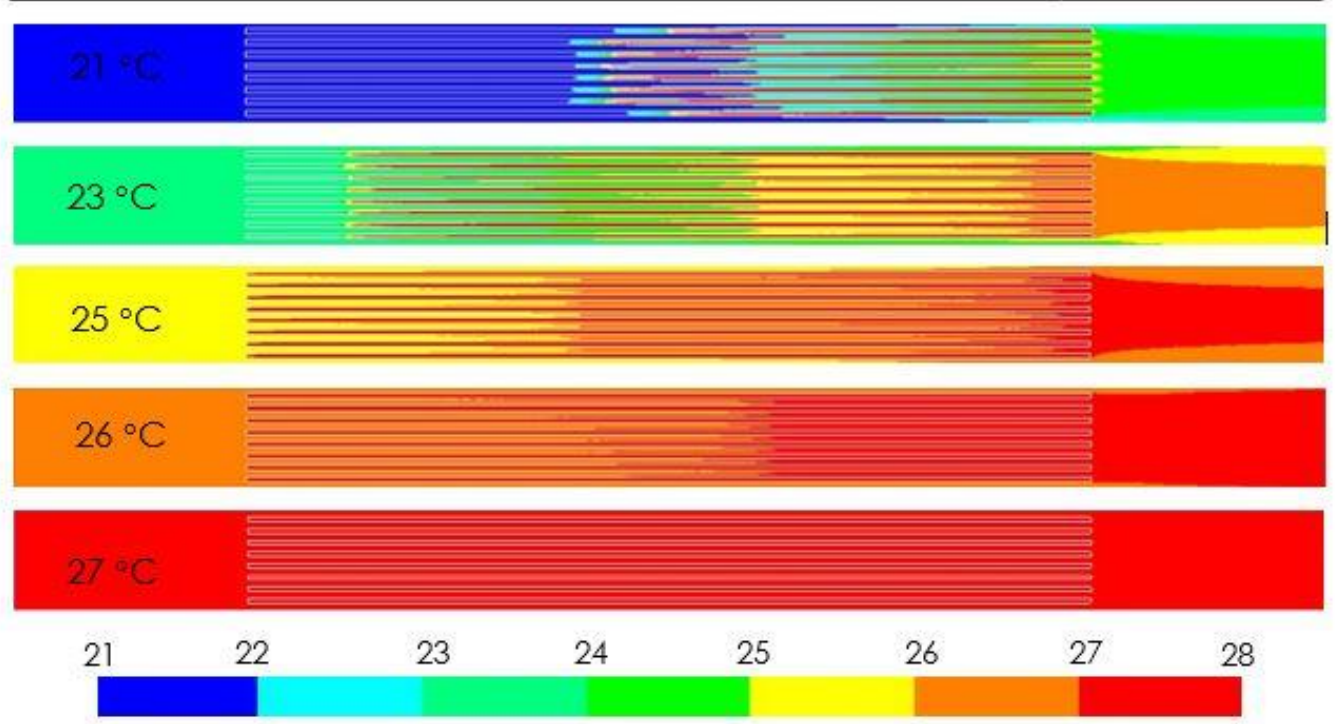

(b) Temperature $\left({ }^{\circ} \mathrm{C}\right)$

541 Figure 10: Contours of (a) PCM liquid fraction (b) temperature after 4 hours of charging for inlet air

542 temperatures $21,23,25,26$, and $27^{\circ} \mathrm{C}$ and at an air flow rate of $213 \mathrm{~L} / \mathrm{s}$.

544 Figure 11 (a) and (b) demonstrate the variation in the PCM liquid fraction and the outlet air 545 temperature, respectively, during the discharging process for the adopted inlet air temperatures, 546 at an air flow rate $53 \mathrm{~L} / \mathrm{s}$. It is evident from Figure 11a that the full PCM melting took 547 approximately around $10.87,13.15$, and 16.76 hours, when the operating air temperatures were 54838,36 and $34{ }^{\circ} \mathrm{C}$, respectively. According to Figure $11 \mathrm{~b}$, the outlet air temperature was 
maintained within the thermal comfort boundaries for about 7.54, 10.19, 14.46 hours, when the discharging temperatures were $38,36,34{ }^{\circ} \mathrm{C}$, respectively. These results indicate that the low temperature difference between the PCM and the HTF reduces the heat transfer rate, which results in slower PCM melting and longer comfort duration. The increase of melting time and comfort duration with the temperature decrease is not linear. For instance, a temperature reduction by $2 \mathrm{~K}$ from $38{ }^{\circ} \mathrm{C}$ to $36{ }^{\circ} \mathrm{C}$ resulted in comfort duration extension by $35 \%$, while another decrease from $36{ }^{\circ} \mathrm{C}$ to $34{ }^{\circ} \mathrm{C}$ allowed $42 \%$ increase.

556

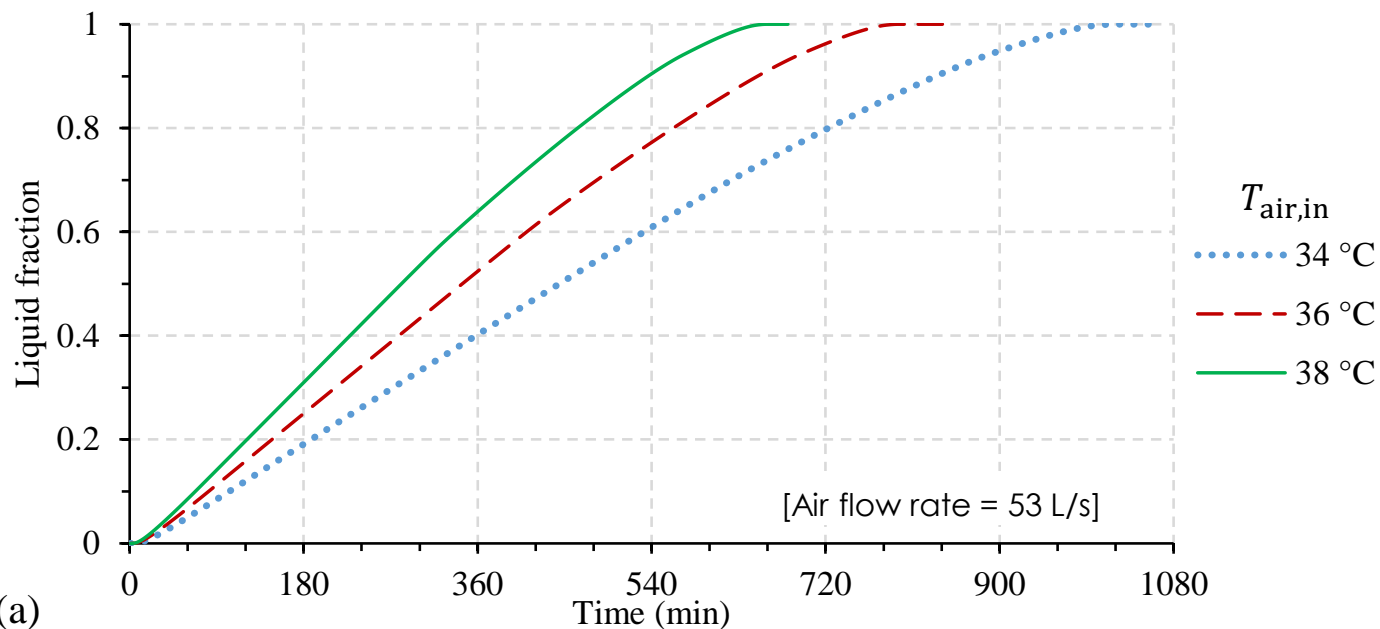

(a)

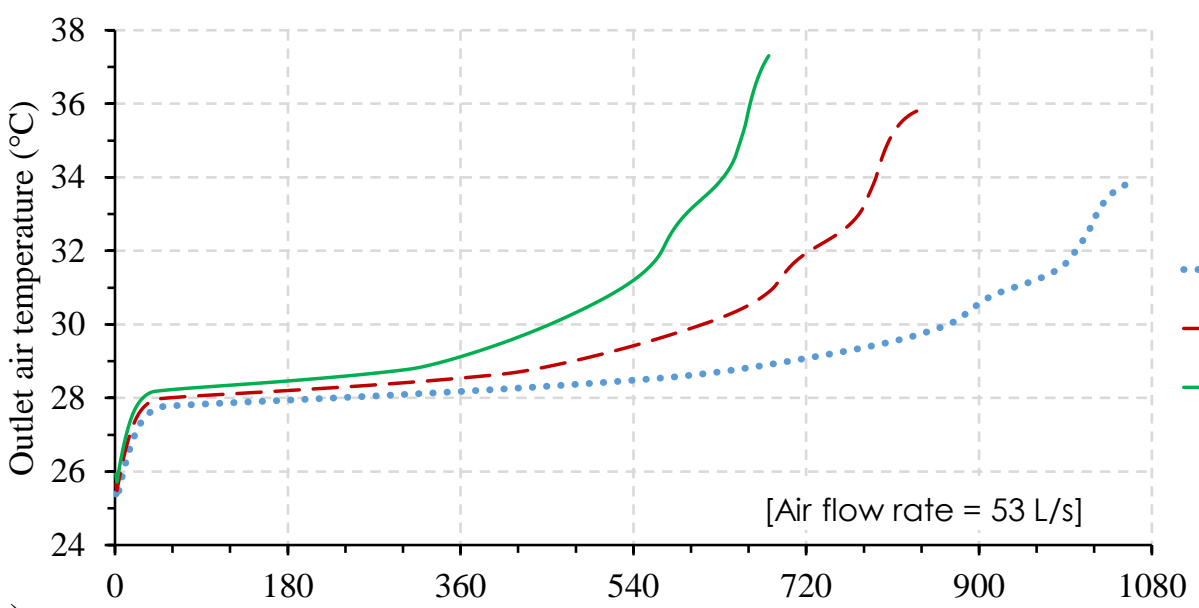

(b)

Time (min)

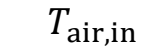

$34{ }^{\circ} \mathrm{C}$

$--36{ }^{\circ} \mathrm{C}$ $38^{\circ} \mathrm{C}$

Figure 11: Variation of (a) PCM liquid fraction and (b) outlet air temperature for different inlet air 559 temperatures during the discharging process.

560 The PCM melting time and thermal comfort duration offered by the system are given in Table

561 7. The contours of PCM liquid fraction and temperature distribution after 4 hours of 562 discharging phase are exemplified in Figure 12. In all cases, it is clear that the comfort level continues until melting of 70-86\% of the PCM. This partial melting is advantageous in boosting

564 the next solidification cycle by $14-30 \%$, which lessens the fan energy utilisation and the 565 charging duration. However, the persistence of the discharging process until attaining the 
566 whole PCM melting may decrease the room temperature, and consequently the load of the 567 supportive conventional cooling system.

568 Table 7: Melting and comfort periods under tested inlet air temperatures at the air flow rate of $53 \mathrm{~L} / \mathrm{s}$.

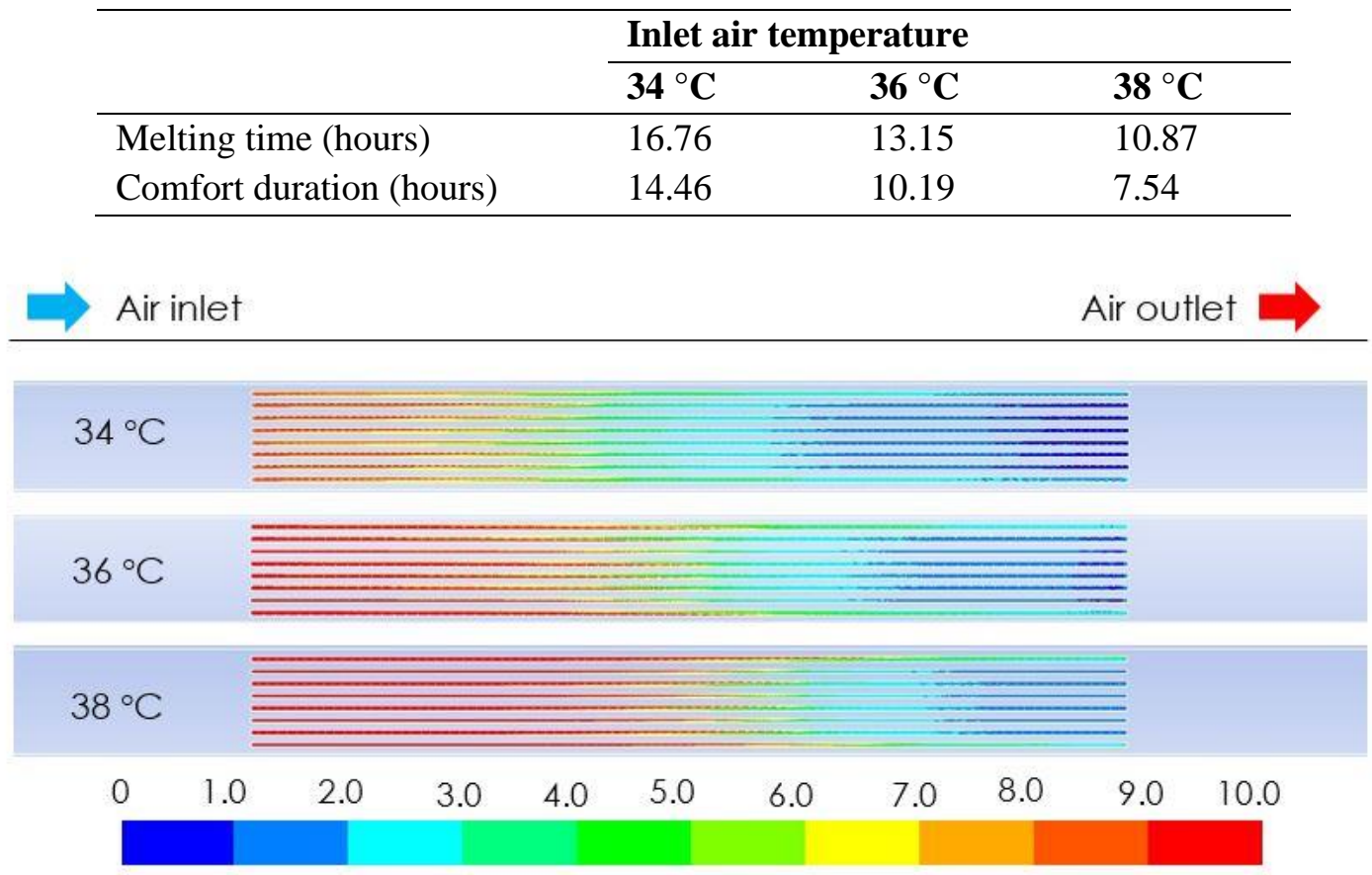

(a) Liquid fraction

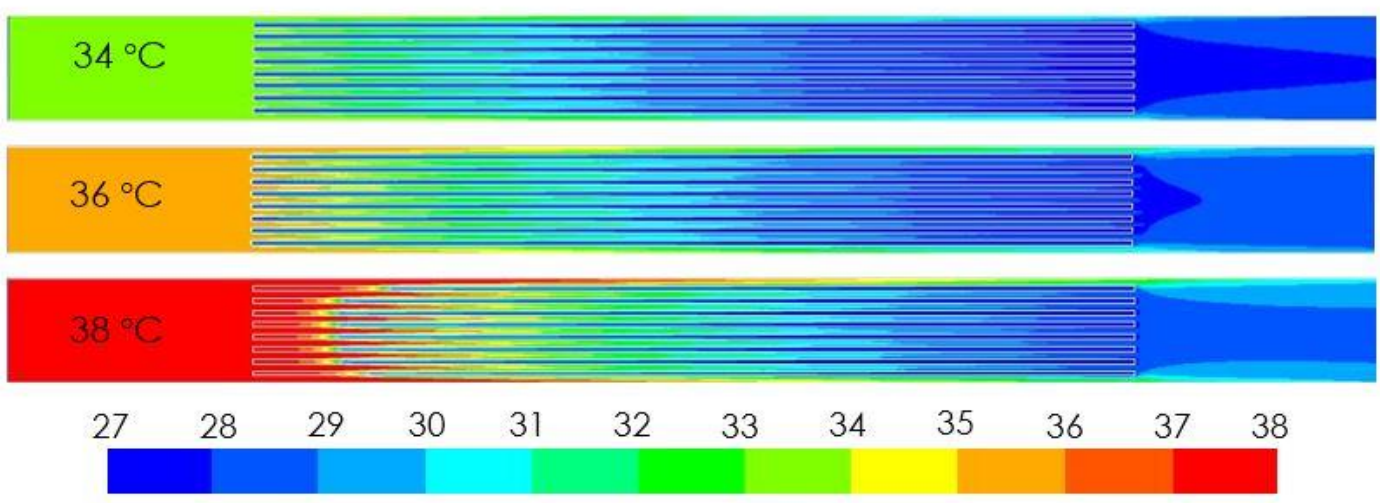

(b) Temperature $\left({ }^{\circ} \mathrm{C}\right)$

570 Figure 12: Contours of (a) PCM liquid fraction (b) temperature after 6 hours of discharging for inlet 571 air temperatures 34,36 , and $38{ }^{\circ} \mathrm{C}$ and at an air flow rate of $53 \mathrm{~L} / \mathrm{s}$. 
573

574

575

576

577

578

579

580

581

582

583

584

585

586

587

588

589

590

\subsection{Influence of air flow rate}

\section{PCM charging}

Figure 13 (a) and (b) present the variation in the PCM liquid fraction and outlet air temperature, respectively, for several air flow rates in the range of 107-533 L/s during the charging process. It is clear that the rate of heat extraction from the PCM was greater at high air flow rates and hence, the solidification is more rapidly, due to the high convective heat transfer coefficient. The full solidification occurred in around 4.2-14.3 hours for air flow rates 533-107 L/s, respectively (Table 8). Boosting air flow rate by a double from $107 \mathrm{~L} / \mathrm{s}$ to $213 \mathrm{~L} / \mathrm{s}$ lessened the charging time by $40 \%$, whereas, an increase by 4 -fold to $533 \mathrm{~L} / \mathrm{s}$ led to a $70.6 \%$ solidification time reduction. This denotes that the decrease in the solidification time is considerable at the low air flow rates $(107-320 \mathrm{~L} / \mathrm{s})$ and gradual at high air flow rates, nearly above $320 \mathrm{~L} / \mathrm{s}$ (Figure 13a). The outlet air temperature data in Figure $13 \mathrm{~b}$ revealed that the higher the air flow rate, the lower the outlet air temperature would be. Overall, high air flow rates are recommended to solidify the PCM in a short period and providing acceptable comfort temperature at night.

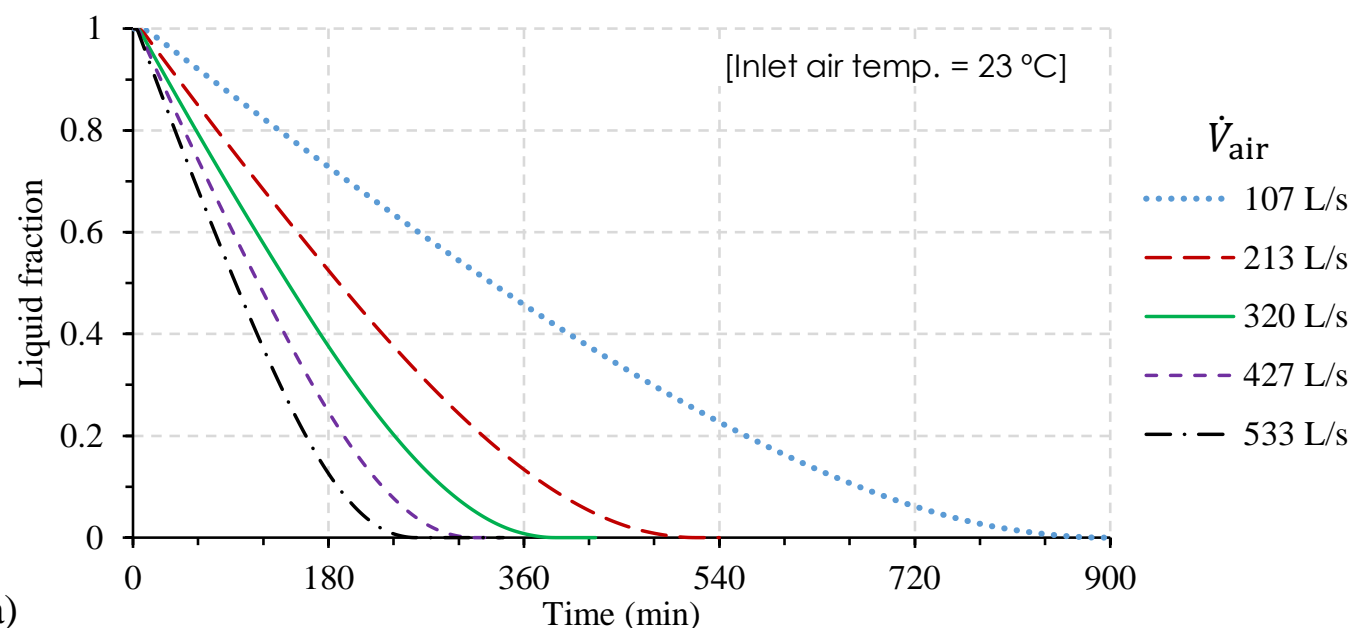

(a)
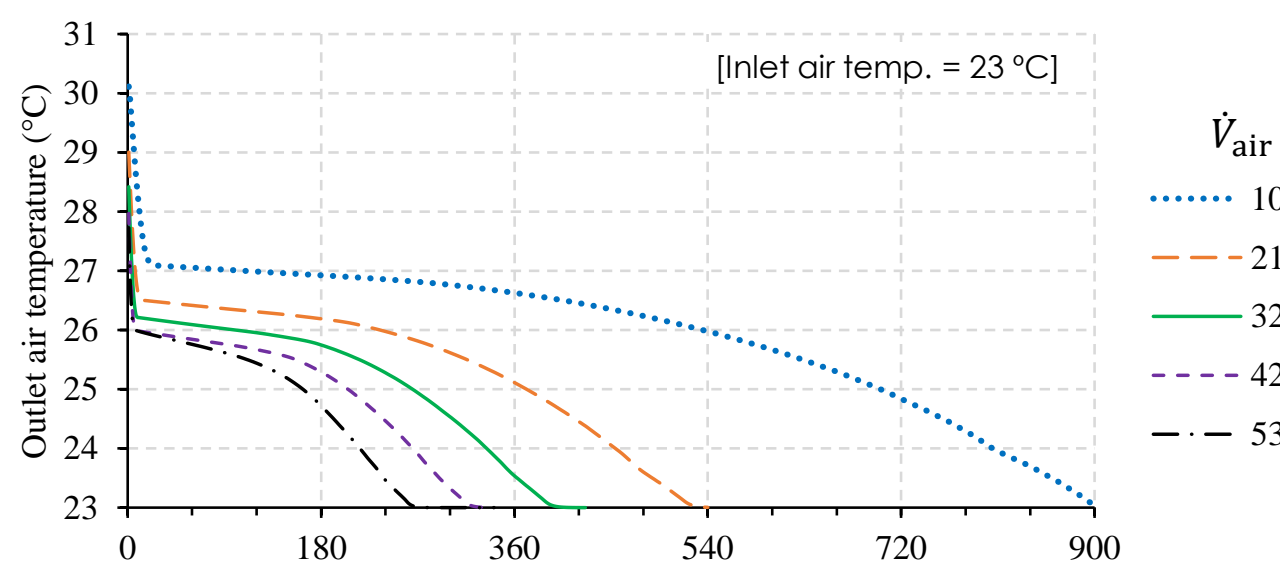

….... $107 \mathrm{~L} / \mathrm{s}$

$--213 \mathrm{~L} / \mathrm{s}$

$320 \mathrm{~L} / \mathrm{s}$

$----427 \mathrm{~L} / \mathrm{s}$

$-\cdot-533 \mathrm{~L} / \mathrm{s}$

(b)

Time (min)

Figure 13: Variation of (a) PCM liquid fraction and (b) outlet air temperature for different air flow rates during the charging process. 
Table 8: Solidification time under tested air flow rates at an inlet temperature of $23{ }^{\circ} \mathrm{C}$.

\begin{tabular}{llllll}
\hline \multicolumn{5}{c}{ Air flow rate } \\
\cline { 2 - 6 } & $\mathbf{1 0 7} \mathbf{~} / \mathbf{s}$ & $\mathbf{2 1 3 ~ \mathbf { ~ } / \mathbf { s }}$ & $\mathbf{3 2 0} \mathbf{~ L} / \mathbf{s}$ & $\mathbf{4 2 7} \mathbf{~ L} / \mathbf{s}$ & $\mathbf{5 3 3 ~ \mathbf { ~ } / \mathbf { s }}$ \\
\hline Solidification time (hours) & 14.3 & 8.4 & 6.3 & 5.1 & 4.2
\end{tabular}

593 Figure 14 (a) and (b) illustrate the variation of the PCM liquid fraction and the outlet air 594 temperature, respectively, for several air flow rates between $13 \mathrm{~L} / \mathrm{s}$ and $107 \mathrm{~L} / \mathrm{s}$. It is evident 595 that the greater the air flow rate, the shorter the melting time and hence, the comfort duration 596 as a result of the high convective heat transfer coefficient (Figure 14a). In all cases, the outlet 597 air temperature was within the comfort zone with varying durations, where the lower air flow 598 rate maintaining longer comfort period (Figure 14b).

599 The melting time and the thermal comfort durations for the tested air flow rates are presented 600 in Table 9. It is evident that the variation in the melting time and the comfort duration with the 601 air flow rate is not linear. enhancing the air flow rate from $13 \mathrm{~L} / \mathrm{s}$ to $27 \mathrm{~L} / \mathrm{s}$ reduced the melting 602 and comfort periods by approximately 40\%, while a 7-fold enhancement to $107 \mathrm{~L} / \mathrm{s}$ resulted in 603 melting and comfort time reductions by $70.6 \%$. This implies that the influence of the air flow 604 rate on the PCM melting and comfort durations is considerable in the case of low flow rates $605(13-53 \mathrm{~L} / \mathrm{s})$ and lower at high flow rates, possibly more than $53 \mathrm{~L} / \mathrm{s}$. It can be stated that air 606 flow rates in the range of 27-53 L/s ( 2-4 ACH) are appropriate for ventilative cooling in 607 domestic buildings, allowing for comfort durations between 19.6-10.2 hours, respectively.

608 Significantly, the air flow rate plays a crucial role in the heat exchange rate between the 609 circulated air and the PCM. Low air flow rates are more advantageous during the discharging 610 process for indoor air supply at a lower and steady temperature, compared to high air flow 611 rates. 

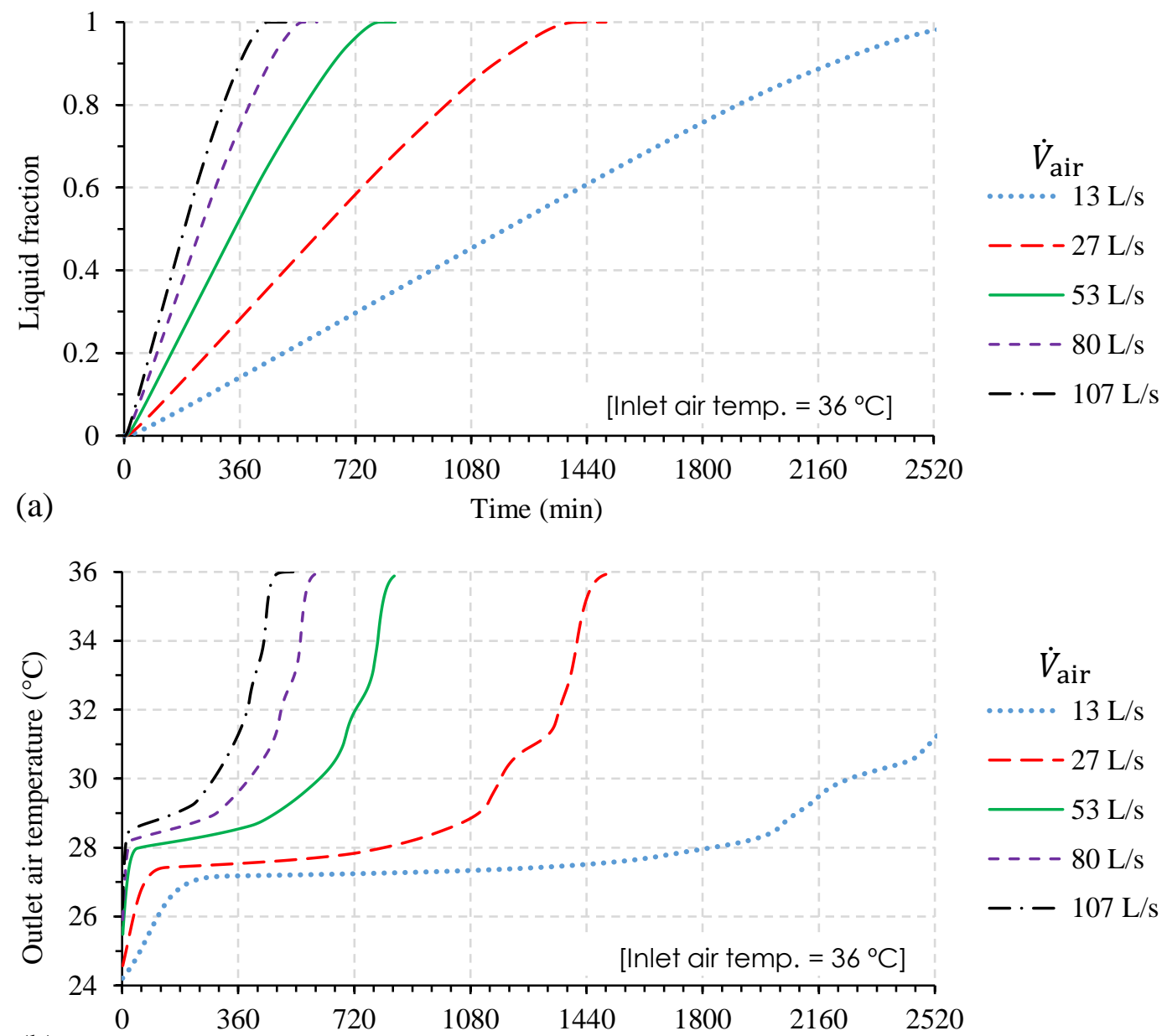

614 Figure 14: Variation of (a) PCM liquid fraction and (b) outlet air temperature for different air flow 615 rates during the discharging process.

616 Table 9: Melting time and comfort durations under tested air flow rates at inlet air temperature $36{ }^{\circ} \mathrm{C}$.

\begin{tabular}{llllll}
\hline & \multicolumn{2}{l}{ Air flow rate } \\
\cline { 2 - 6 } & $\mathbf{1 3 ~ \mathbf { ~ } / \mathbf { s }}$ & $\mathbf{2 7} \mathbf{~ L / s}$ & $\mathbf{5 3 ~ \mathbf { s }}$ & $\mathbf{8 0 ~ \mathbf { s }} \mathbf{s}$ & $\mathbf{1 0 7} \mathbf{~ L} / \mathbf{s}$ \\
\hline Melting time (hours) & 42.5 & 23.4 & 13.2 & 8.8 & 7.0 \\
Comfort duration (hours) & 37.5 & 19.6 & 10.2 & 6.6 & 4.7 \\
\hline
\end{tabular}

618 The variation of the predicted pressure drop and fan power consumption with the air volume

619 flow rate is presented in Table 10 and Figure 15, for the base model with a $10 \mathrm{~mm}$ PCM module 620 thickness and $15 \mathrm{~mm}$ air channel height. The tested range of air flow rates involved the charging 621 and discharging operation. It is clear that the pressure drop enhances with the air flow rate with 622 a polynomial relation. The pressure drop varied between $0.68 \mathrm{~Pa}$ and $71.19 \mathrm{~Pa}$, for air flow 623 rates between $27 \mathrm{~L} / \mathrm{s}$ and $533 \mathrm{~L} / \mathrm{s}$, respectively. 
624 Table 10: Predicted pressure drop and fan power consumption for different air flow rates.

\begin{tabular}{lll}
\hline Air flow rate $(\mathbf{L} / \mathbf{s})$ & Pressure drop $(\mathbf{P a})$ & Fan power $(\mathbf{W})^{*}$ \\
\hline 27 & 0.68 & 0.04 \\
53 & 1.75 & 0.18 \\
80 & 3.35 & 0.52 \\
107 & 5.23 & 1.10 \\
213 & 16.31 & 6.94 \\
320 & 29.74 & 19.41 \\
427 & 48.14 & 42.37 \\
533 & 71.19 & 78.73 \\
\hline
\end{tabular}

* Calculated assuming fan efficiency of 0.55 and an air temperature of $27^{\circ} \mathrm{C}$.

625

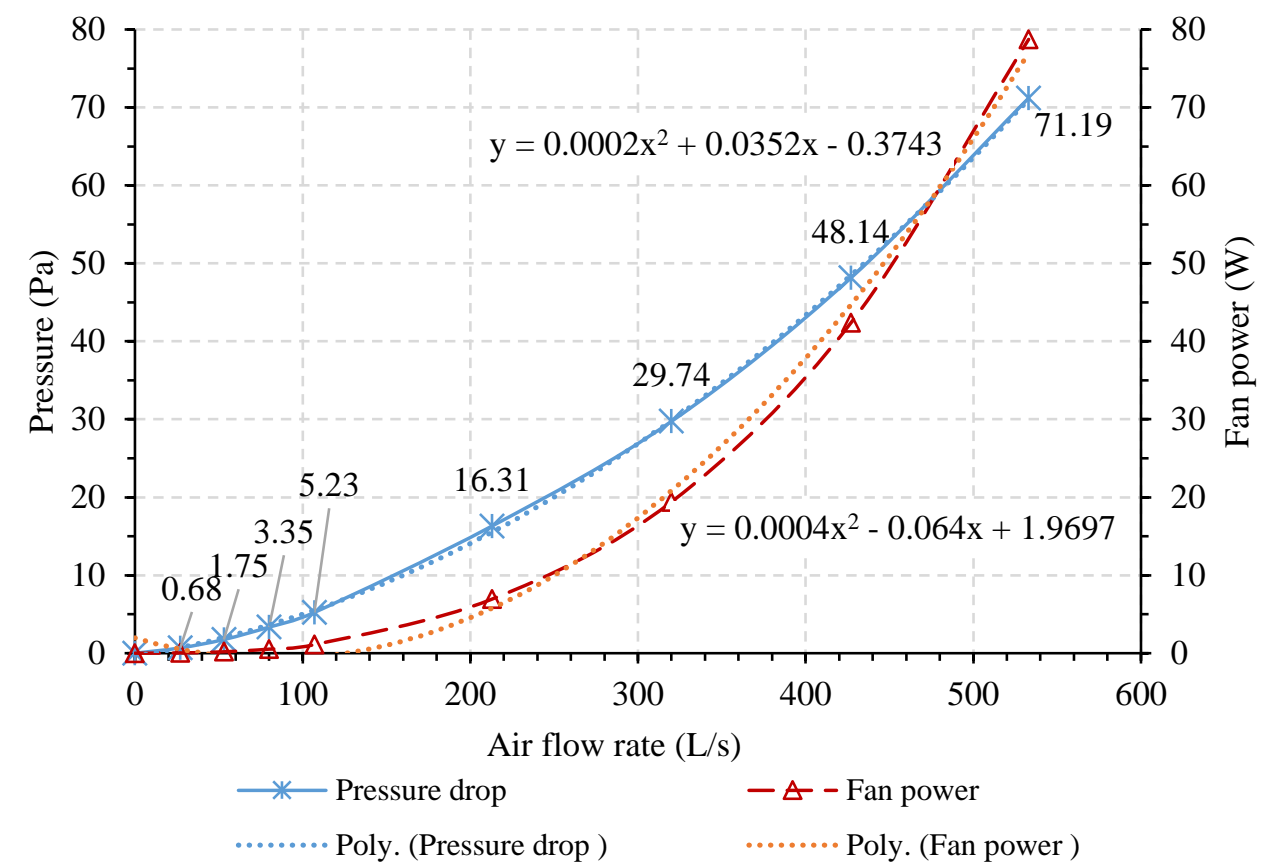

627 Figure 15: Predicted pressure drop and fan power consumption for different air flow rates. 
630 The variation of PCM liquid fraction and outlet air temperature for all tested cases during a 631 complete charging phase is shown in Figure 16 (a) and (b), respectively.

632
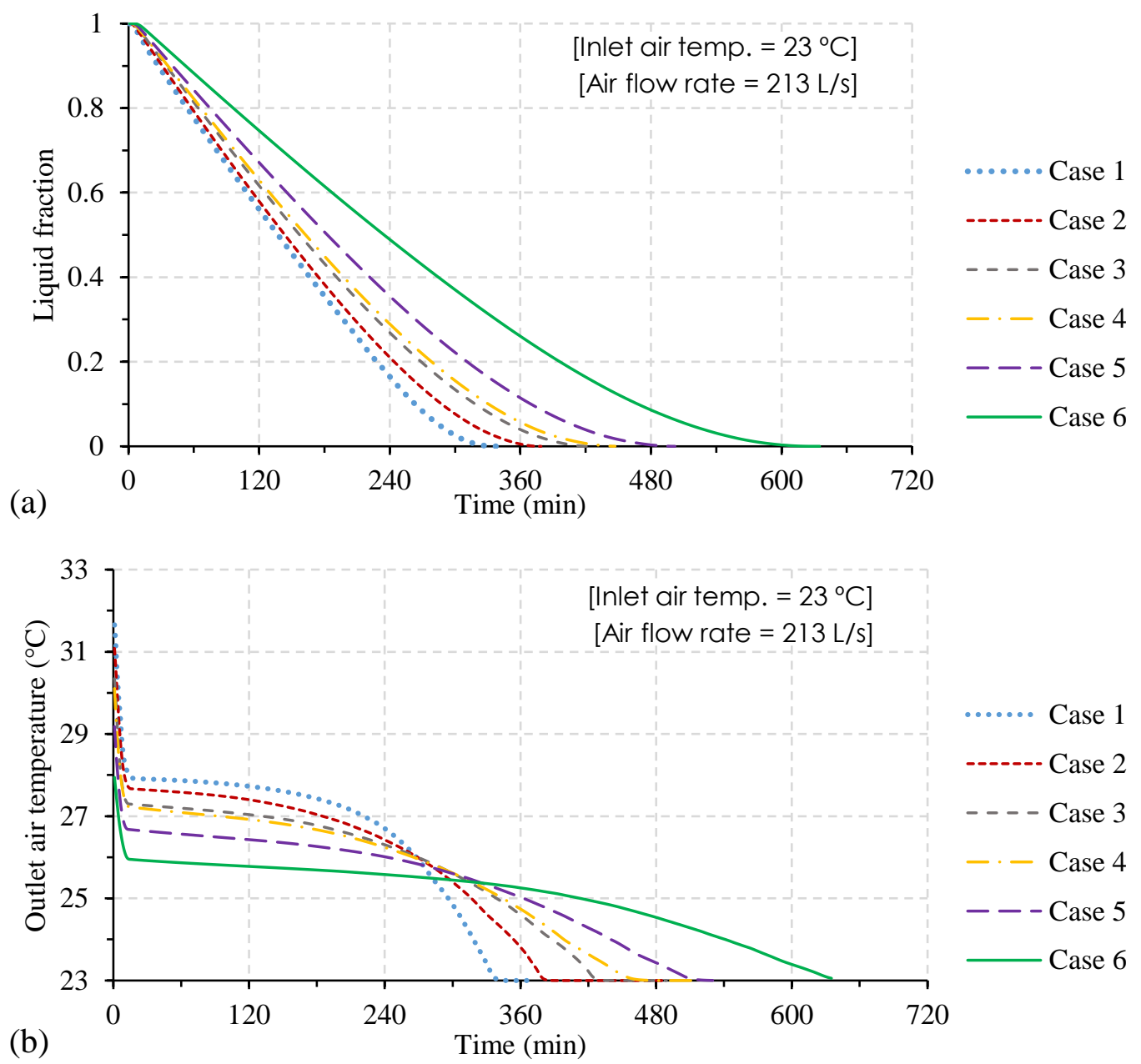

633 (b)

634 Figure 16: Variation of (a) PCM liquid fraction and (b) outlet air temperature during the charging 635 process for different TES configurations.

636 As illustrated in Figure 16a, the solidification rate varied depending on the PCM thickness and 637 the air channels height. The fastest solidification took place in case 1 (5.5 hours) when the 638 PCM thickness and the air channels height were at the lowest level (5 mm). While around 10.1 639 hours are required to achieve the full solidification in case 6 , where wider air channels (25 mm) 640 and thicker PCM modules $(10 \mathrm{~mm})$ exist. Figure $16 \mathrm{~b}$ demonstrates that the TES system 641 configuration has a considerable impact on the outlet air temperature during the charging phase.

642 Throughout the transition phase, the outlet temperature was in the range $26-28{ }^{\circ} \mathrm{C}$, higher than 643 the inlet temperature by 3-5 K for cases 1-6, respectively. The outlet temperature was higher 
644 in the case of the narrow air channels and thinner PCM modules, as a result of the heat transfer 645 rate enhancement. This could be attributed to the higher air speed in the narrow channels than 646 in wide channels. Following the phase change period, the outlet temperature drops reaching 647 the inlet temperature at varying periods depending on the heat transfer rate.

648 The solidification periods for all test cases are compared in Figure 17. For the same PCM 649 thickness, increasing the air channel by $5 \mathrm{~mm}$ leads to about $11-12 \%$ increase in the 650 solidification time. This denotes that the rate of heat discharging from the PCM is better in the 651 case of narrow air channels than the wide channels. For cases with the same air channels height 652 but different PCM thicknesses (cases 2 and 4 or cases 3 and 5), the solidification period was 653 shorter by around 16-17\% in the cases with thinner PCM modules, i.e. cases 2 and 3.

654 It is observed from Figure 17 that despite the ratio of the PCM thickness to the air channel 655 height in cases 1 and 4 is 1:1, where the main duct heights are varied slightly by $5 \mathrm{~mm}$ (Table 656 4), the solidification period was $24 \%$ shorter in case 1 with thin PCM modules and narrow air 657 flow channels. Also, it can be noticed that the difference in solidification time for cases 3 and 6584 was only $4 \%$, although the main duct height in case 3 was double of that for case 4 . Overall, 659 these results prove the substantial impact of both PCM thickness and air channels height on the 660 heat transfer rate, with a greater impact for the PCM thickness.

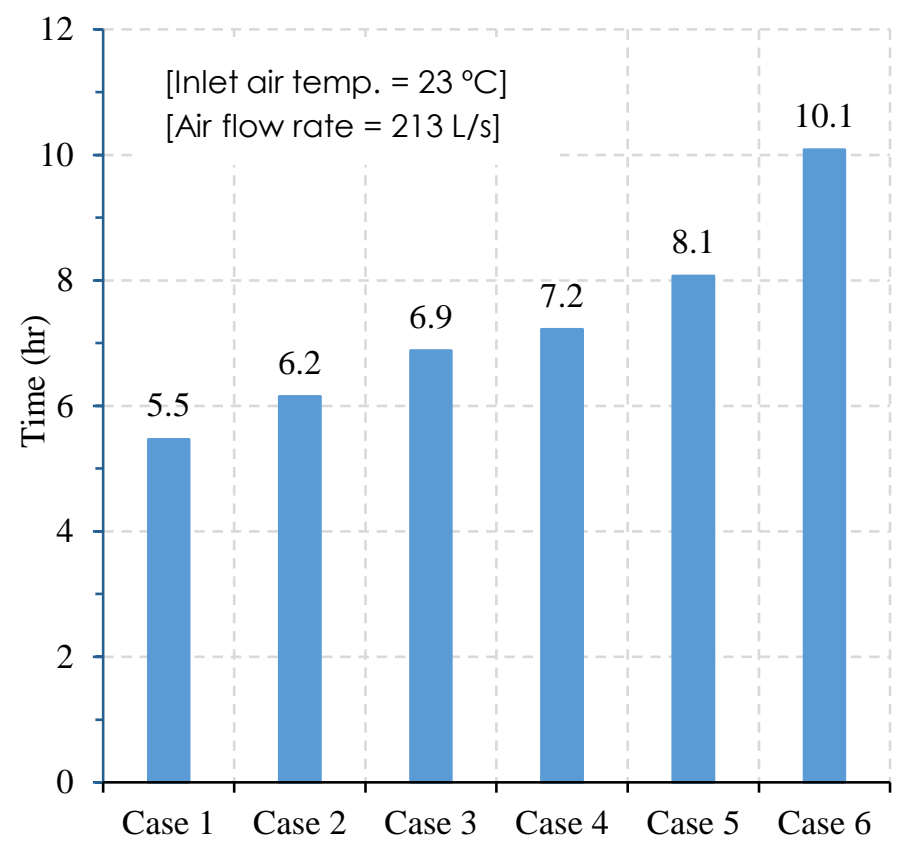


663 Figure 18 depicts the temperature contours in the PCM and air domains after 4 hours of the 664 charging process. It is obvious that the front part of the PCM modules reached the steady-state 665 temperature at $23{ }^{\circ} \mathrm{C}$ in all cases with the highest percentage in case 1 . The temperatures at the 666 top and bottom PCM modules were lower than in the other modules, owing to the higher rate 667 of heat removal from the PCM caused by the cooler air flowing through the upper and lower 668 channels compared to the air passing through the middle of the main duct.
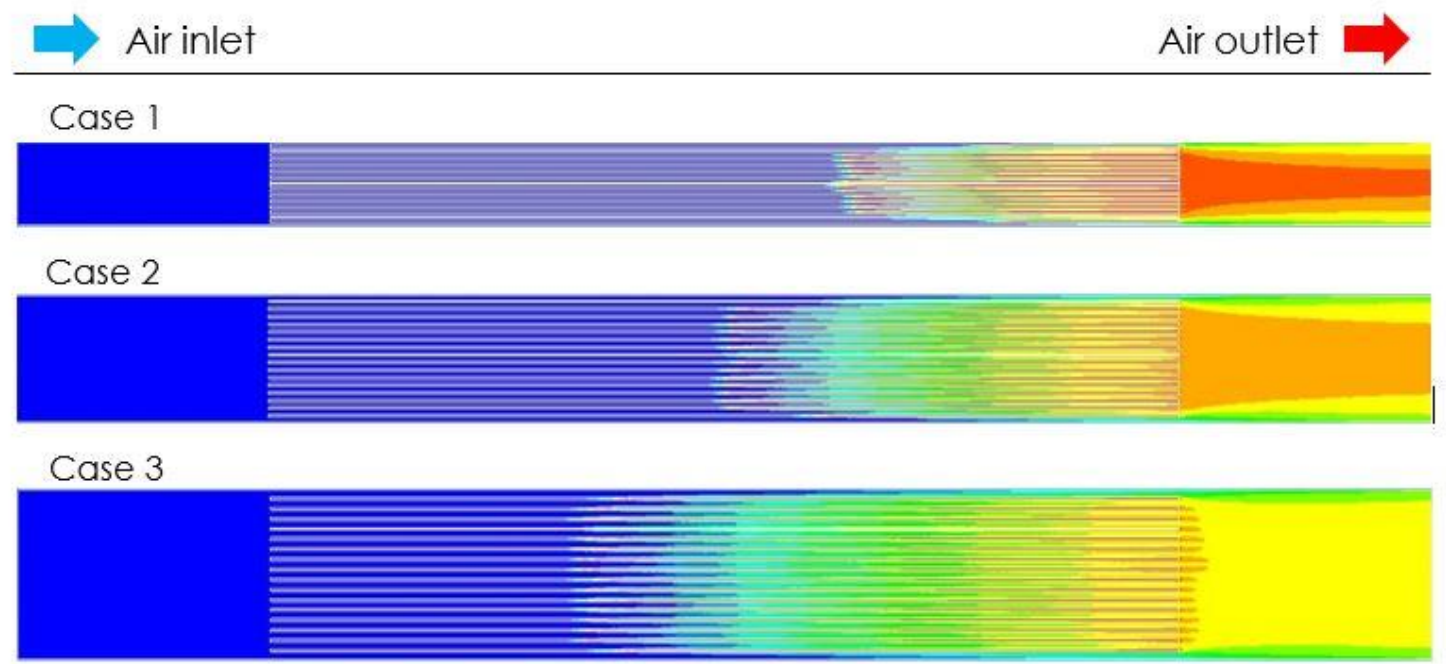

Case 4

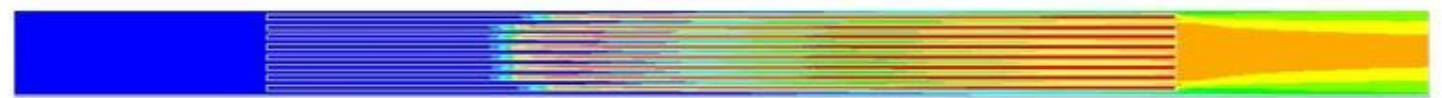

Case 5

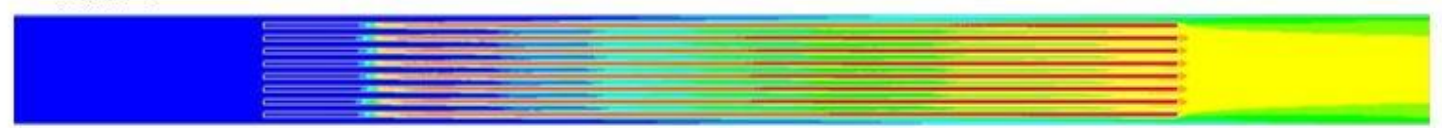

Case 6

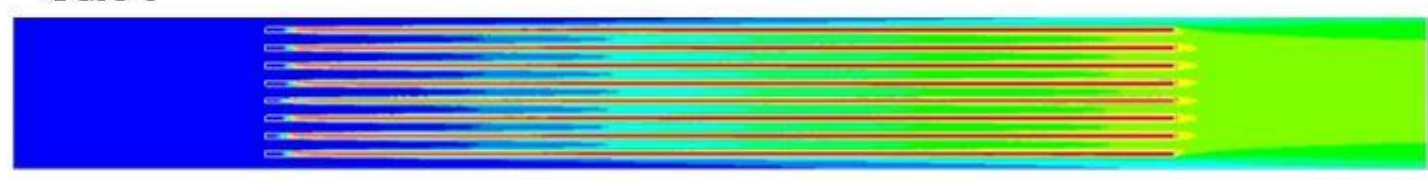

Temperature scale $\left({ }^{\circ} \mathrm{C}\right)$

23

24

25

26

27

28

669

670 Figure 18: Contours of temperature distribution in the tested TES configurations after 4 hours of

671 charging at inlet air temperature $23{ }^{\circ} \mathrm{C}$ and air flow rate $213 \mathrm{~L} / \mathrm{s}$. 
673 The variation of the PCM liquid fraction and the outlet air temperature during the discharging 674 process are demonstrated in Figure 19 (a) and (b), respectively, for the tested cases with 675 different configurations.

676 It is clear from Figure 19a that the melting time varies according to the TES configuration. The 677 quickest melting was achieved after 10.7 hours in case 1, due to the high thermal absorption 678 rate by the PCM, as a result of the compact design with a $5 \mathrm{~mm}$ height for both the PCM module 679 and the air channel. On the other hand, it took almost 15.2 hours for the full melting process to 680 complete in case 6, where the PCM thickness and the air channels height were $10 \mathrm{~mm}$ and 25 $681 \mathrm{~mm}$, respectively.

682 As shown in Figure 19b, the outlet air temperatures were within the comfort zone for around 68310 hours. During the transition phase, the temperatures were between $27{ }^{\circ} \mathrm{C}$ and $29{ }^{\circ} \mathrm{C}(\mathrm{PCM}$ 684 melting range) for cases $1-5$ and higher than $29{ }^{\circ} \mathrm{C}$ for case 6 . This was due to the large PCM 685 thickness coupled with the high ratio of channel height to the PCM thickness $(2.5: 1)$ in case 6 686 compared to the other cases, which resulted in a poor heat transfer rate between the PCM and 687 the HTF.

688 Since the variations in the comfort duration were relatively small, especially in the case of thin 689 PCM modules, the aim during the discharging phase was to achieve the largest drop in the 690 outlet air temperature below the inlet temperature. Configurations with thinner PCM modules 691 coupled with small air channel height permitted a larger outlet air temperature drop. For 692 instance, the maximum temperature drop obtained was around $10 \mathrm{~K}$ in case 1 , when the outlet 693 temperature was maintained at $26^{\circ} \mathrm{C}$ for around 7 hours. While a lower temperature drop was 694 achieved in case 6 , where the outlet temperature fluctuated between $29^{\circ} \mathrm{C}$ and $30{ }^{\circ} \mathrm{C}$.

695 In most cases, it can be stated that the full melting was not the major concern during the 696 discharging phase, rather, the main target was to cool the air to the comfort level for the longest 697 possible period. 

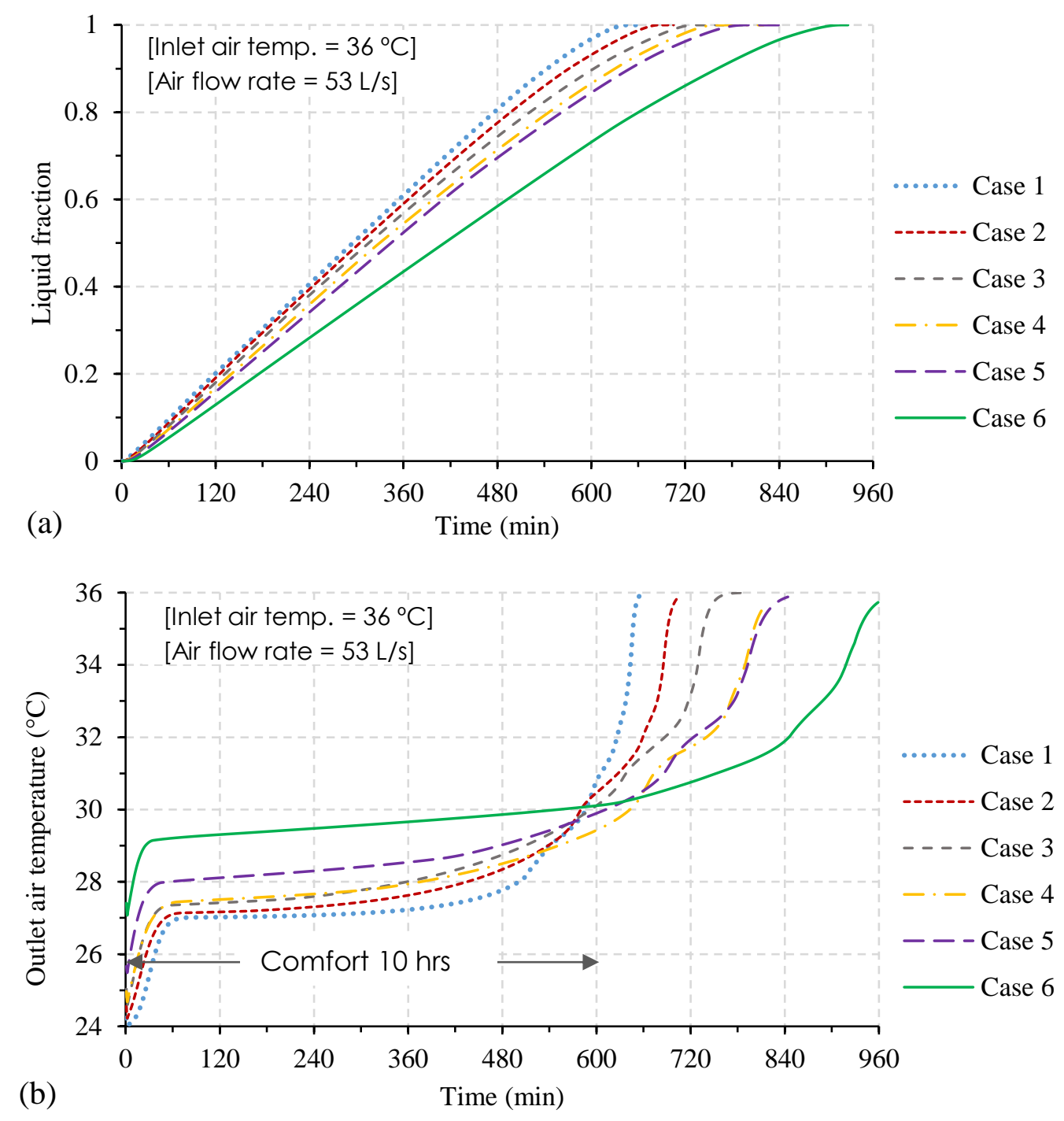

700 Figure 19: Variation of (a) PCM liquid fraction and (b) outlet air temperature during the discharging

701 process for different TES configurations.

702 The required time for full PCM melting along with the thermal comfort durations for all tested

703 cases are presented in Figure 20. It is obvious that the melting rate and thermal comfort

704 durations varied slightly according to the TES configuration. For similar PCM thickness, when

705 the air channels are increased by $5 \mathrm{~mm}$, the thermal comfort period reduced by around $1 \%$ -

$7064.5 \%$, with lower variations in the case of thinner PCM (cases 1-3). This implies that the impact

707 of the channel height on the thermal comfort duration is intangible in the case of thin PCM (5

$708 \mathrm{~mm})$ compared to thick PCM $(10 \mathrm{~mm})$. For cases with the same air channels height but different

709 PCM thicknesses (cases 2 and 4 or cases 3 and 5), the comfort period was longer in the case of

710 thick PCM than the thin due to the thermal resistance, as indicated earlier. However, the impact

711 of the PCM thickness was less with increasing the air channels height. For example, the

712 enhancement in the comfort period was $9 \%$ from case 2 to 4 , and $5 \%$ from case 3 to 5 . These 
713 results demonstrate that the PCM thickness is more influential on the discharging performance 714 than the air channels height.

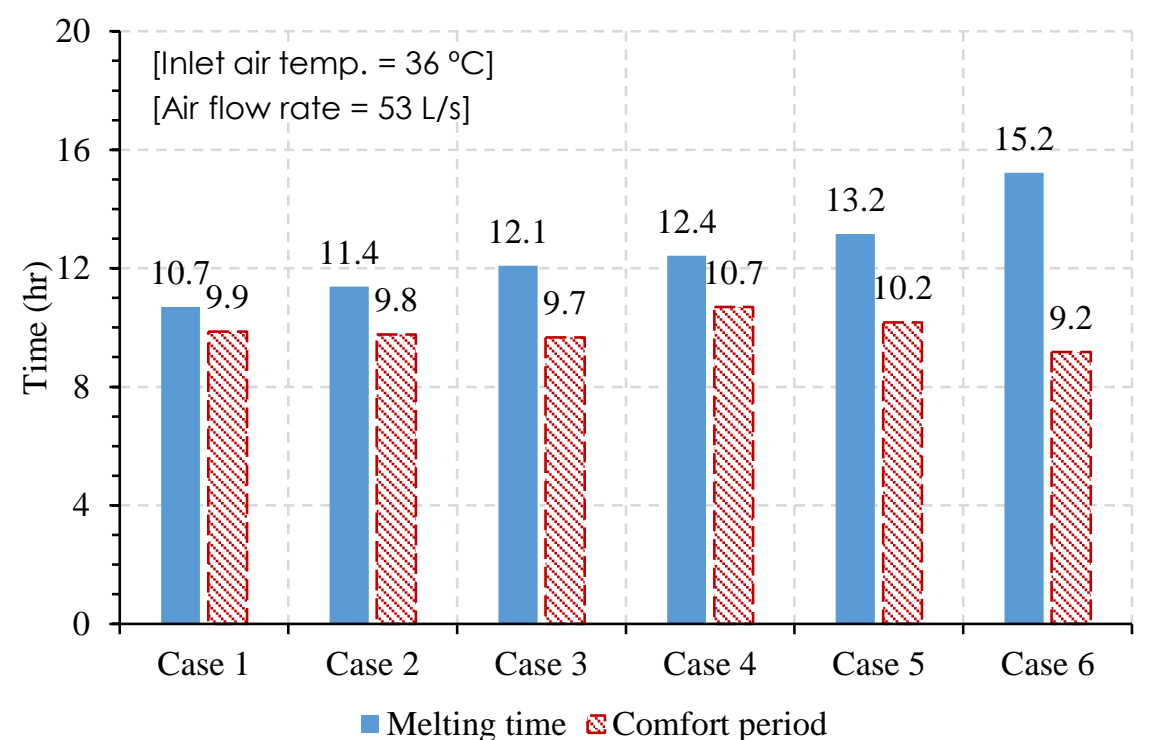

Figure 20: PCM melting time and comfort duration for different TES configurations.

717 The contours of temperature distribution in the PCM and air domains in all investigated 718 configurations after 4 hours of the discharging process are depicted in Figure 21. It is evident 719 that the melting fraction of the PCM was the highest in case 1, where the heat transfer rate was 720 at the highest. The front section of the PCM modules melted quicker than the back modules, 721 as a result of the gradual drop in the temperature difference between the PCM and the air 722 towards the outlet.

723 Since the variations in the comfort durations were relatively small among all test cases, besides 724 considering the enhancement of the charging performance, an optimised TES system 725 comprising thin PCM modules coupled with narrow air flow channels could be considered for 726 both charging and discharging processes. Through such a system, the charging process can be 727 accelerated. The daytime thermal comfort could be maintained at a temperature lower than 728 which supplied by a system with thicker PCM and wider air flow channels. In addition to the 729 enhanced thermal performance, the compact TES arrangement requires smaller space for the 730 system installation. 


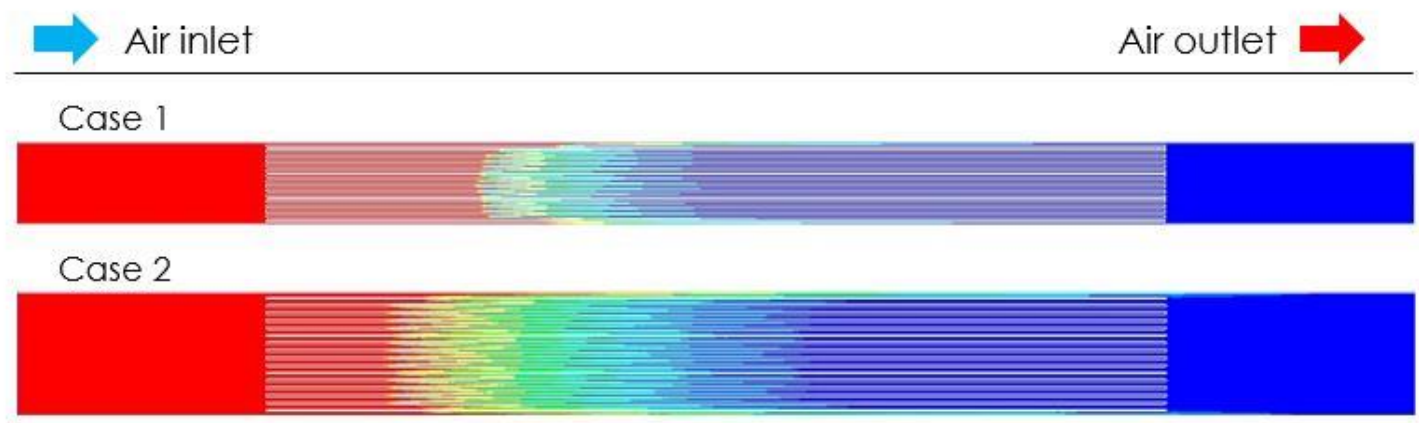

Case 3

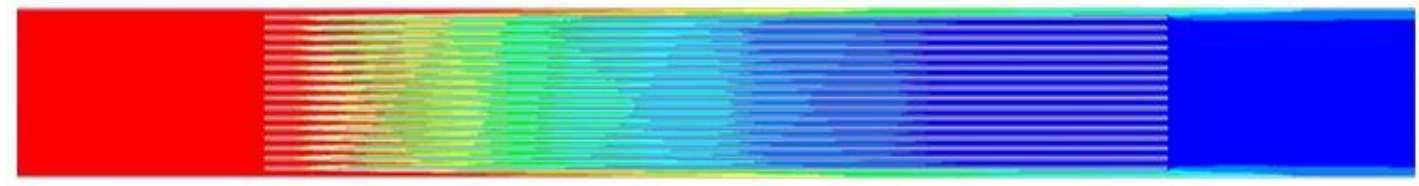

Case 4

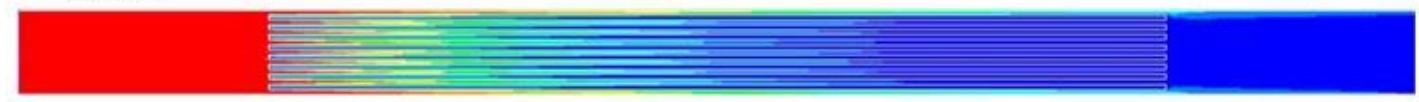

Case 5

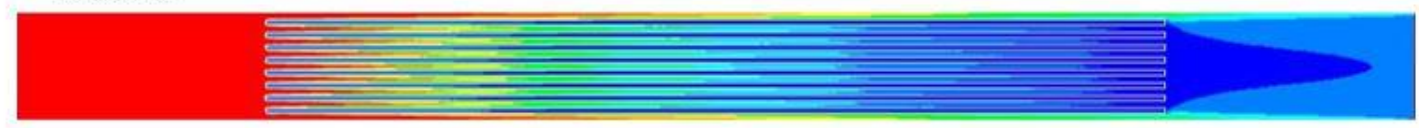

Case 6

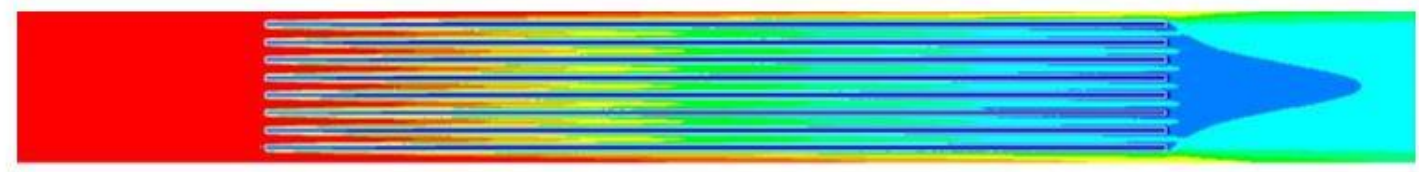

Temperature scale $\left({ }^{\circ} \mathrm{C}\right)$

\begin{tabular}{llllllllll}
27 & 28 & 29 & 30 & 31 & 32 & 33 & 34 & 35 & 36 \\
\hline
\end{tabular}

731

732 Figure 21: Contours of temperature distribution in the tested TES configurations after 4 hours of 733 discharging at inlet air temperature $36{ }^{\circ} \mathrm{C}$ and air flow rate $53 \mathrm{~L} / \mathrm{s}$. 


\subsection{Performance evaluation}

736

737

738

739

740

742

743 During the moderate summer conditions (March and April), it is clear that there is a

\subsubsection{Potential system performance under real climate conditions}

Based on the TES system configuration, boundary conditions, and the suitable period for PCM charging during summer months in Khartoum summarised in Table 11; the potential system performance under the real conditions can be estimated.

Table 11: Suitable conditions for PCM charging in a reference day during summer and transitional months in a hot-arid climate of Khartoum

\begin{tabular}{lllllllll}
\hline & Mar. & Apr. & May & Jun. & Jul. & Aug. & Sep. & Oct. \\
\hline Charging period (hr) & 11 & 8 & 2 & 3 & 3 & 5 & 3 & 3 \\
Avg. ambient temperature $\left({ }^{\circ} \mathrm{C}\right)$ & 23 & 24 & 27 & 27 & 26 & 26 & 26 & 26 \\
\hline
\end{tabular}
considerable cooling potential with adequate time up to 11 hours for full PCM charging (Table 11). Therefore, the entire cooling load could be covered through the free cooling strategy and the full solidification would be possible during the night following a full PCM melting. The average time required for achieving a full PCM solidification was between 6-8 hours with the selected air flow rate, while the actual night-time suitable for charging process ranges between 8 and 11 hours. This allows system operation with a lower air flow rate, leading to a reduction in fan power consumption.

751 On the other hand, during peak summer conditions (May-October) where the cooling demand is dominant, provision of full cycles of solidification and melting is quite challenging, at which period; the ambient temperature is high relative to PCM transient temperature and the available time for charging is quite limited between 3 and 5 hours only (Table 11). However, the energy storage capacity of the PCM could be enhanced with the assistance of some natural cooling strategies such as evaporative cooling, ground cooling and radiative cooling to allow PCM charging with cooler air and extending the charging period. The benefits of incorporating natural cooling strategies into free cooling systems also extend to the reduction of fan energy requirements, as lower air velocities can be used in this case. 
Table 12 presents the predicted pressure drop and fan power consumption for the tested 6 TES configurations (described in Table 4) at air flow rates $213 \mathrm{~L} / \mathrm{s}$ and $27 \mathrm{~L} / \mathrm{s}$ for the charging and discharging processes, respectively. It is inferred that the TES geometrical configuration has a noticeable effect on the fan power consumption. The variation in the fan power consumption was considerable between the systems with narrow air flow channels and wide channels. For instance, the fan power was lower in case 5 (10 mm PCM thickness and $15 \mathrm{~mm}$ air channels height) by around $81 \%$ than case 1 ( $5 \mathrm{~mm}$ for both PCM thickness and air channels height). On the other hand, during the discharging phase, the required fan power for cooling extraction is generally low. The maximum pressure drop and fan power consumption were estimated at 8.5 $\mathrm{Pa}$ and $0.38 \mathrm{~W}$, respectively, at the air flow rate of $27 \mathrm{~L} / \mathrm{s}$, which are obtained in the most compacted TES design (case 1).

773 Though a compact TES unit allows better thermal performance as previously discussed, a high 774 fan power use is predicted during the charging process as shown in Table 12. Therefore, optimisation of the TES system design should depend on the evaluation of the entire performance including the fan power use, the cooling load delivered, and the potential energy savings in comparison to the conventional cooling systems operation.

778

Table 12: Predicted pressure drop and fan power consumption for different TES configurations.

\begin{tabular}{|c|c|c|c|c|}
\hline \multirow[b]{3}{*}{ Case } & \multicolumn{2}{|l|}{ Charging phase } & \multicolumn{2}{|c|}{ Discharging phase } \\
\hline & \multicolumn{2}{|c|}{ Air flow rate of $213 \mathrm{~L} / \mathrm{s}$} & \multicolumn{2}{|c|}{ Air flow rate of $27 \mathrm{~L} / \mathrm{s}$} \\
\hline & $\begin{array}{l}\text { Pressure drop } \\
(\mathrm{Pa})\end{array}$ & $\begin{array}{l}\text { Fan power* } \\
\text { (W) }\end{array}$ & $\begin{array}{l}\text { Pressure drop } \\
\text { (Pa) }\end{array}$ & $\begin{array}{l}\text { Fan power* } \\
\text { (W) }\end{array}$ \\
\hline Case 1 & 123.3 & 54.39 & 8.5 & 0.42 \\
\hline Case 2 & 18.39 & 10.01 & 1.07 & 0.05 \\
\hline Case 3 & 5.59 & 3.77 & 0.33 & 0.02 \\
\hline Case 4 & 47.78 & 24.74 & 2.26 & 0.11 \\
\hline Case 5 & 16.31 & 10.21 & 0.68 & 0.03 \\
\hline Case 6 & 3.63 & 3.34 & 0.16 & 0.01 \\
\hline
\end{tabular}

* Calculated assuming fan efficiency of 0.55 and an air temperature of $27{ }^{\circ} \mathrm{C}$. 
783 The operational performance was assessed for two TES system configurations; (i) case 1: a 784 compact system with a $5 \mathrm{~mm}$ of both PCM thickness and air channels height, and (ii) case 5: a 785 less compacted system with a $10 \mathrm{~mm}$ PCM thickness and $15 \mathrm{~mm}$ air channels height. The 786 assessment of the system charging performance was based on the prevailing ambient climate 787 conditions in hot-arid regions presented in Table 11, and two air flow rates of $213 \mathrm{~L} / \mathrm{s}$ and 533 $788 \mathrm{~L} / \mathrm{s}$. In the case of the discharging operation, the evaluation was based on a gradual extraction 789 of the cooling stored in the PCM using an air flow rate of $27 \mathrm{~L} / \mathrm{s}$, which is within the standard 790 ventilation rates recommended for thermal comfort conditions in buildings [58].

791 An energy performance evaluation under four conditions (A-D) has been presented in Table 792 13, which summarises the total cooling produced, fan's energy consumption, and cooling load 793 reduction expected throughout the cooling period from May to October. The total cooling load 794 for the considered summer months was estimated at $577.3 \mathrm{kWh}$ using Energy-Plus simulation 795 tool in a previous study conducted by the authors [53]. It is inferred from Table 13 that a 796 compact system design may provide a higher cooling capacity, owing to the higher heat transfer 797 rate. However, the required power to operate the fan was much high for the range of optimum 798 air flow rates required for the charging process. Significantly, a system with less compacted 799 PCM modules arrangement coupled with a high air flow rate (condition D) has shown the best 800 performance, with the greatest cooling load reduction of about $42.2 \%$.

801 Moreover, a substantial energy saving of around $81.6 \mathrm{kWh}$, accounted for around $67 \%$ is 802 achievable through the best case (Condition D) compared to a typical mechanical vapour 803 compression cooling system of an average COP of 2.0 [65] in the case of operation in hot arid 804 climates.

805 Table 13: A comparison of performance for cases 1 and 5 under air flow rates of 213 L/s and 533 L/s 806 for cooling months in hot-arid climate of Khartoum (May-October).

\begin{tabular}{llllllll}
\hline $\begin{array}{l}\text { TES } \\
\text { arrangement }\end{array}$ & Condition & $\begin{array}{l}\text { Air flow } \\
\text { rate }\end{array}$ & $\begin{array}{l}\text { Pressure } \\
\text { drop }\end{array}$ & $\begin{array}{l}\text { Cooling } \\
\text { produced }\end{array}$ & $\begin{array}{l}\text { Fan } \\
\text { energy } \\
\text { use* }\end{array}$ & $\begin{array}{l}\text { AC } \\
\text { energy } \\
\text { use** }\end{array}$ & $\begin{array}{l}\text { Cooling } \\
\text { load } \\
\text { reduced }\end{array}$ \\
\hline & & $(\mathrm{L} / \mathrm{s})$ & $(\mathrm{Pa})$ & $(\mathrm{kWh})$ & $(\mathrm{kWh})$ & $(\mathrm{kWh})$ & $(\%)$ \\
\hline Case 1 & $\mathrm{A}$ & 213 & 123.3 & 194.9 & 28.3 & 97.6 & $33.8 \%$ \\
& $\mathrm{~B}$ & 533 & 541.6 & 355.3 & 234.1 & 177.5 & $61.5 \%$ \\
Case 5 & $\mathrm{C}$ & 213 & 16.31 & 146.9 & 4.0 & 73.3 & $25.4 \%$ \\
& $\mathrm{D}$ & 533 & 71.19 & 243.9 & 40.2 & 121.8 & $42.2 \%$ \\
\hline
\end{tabular}

* Calculated assuming fan efficiency of 0.55.** Calculated assuming COP of an AC system at 2.0.

Note: Calculations are based on a total cooling load of a room about $577.3 \mathrm{kWh}$ during summer (May-October). 
808 This paper discussed a numerical CFD investigation of a PCM energy storage system for free cooling in buildings. The proposed system was utilised to provide cooling for a standard domestic room during summer in hot-arid climates.

811 Based on the conducted parametric study on the operating conditions and the TES geometrical 812 configuration, the following observations are derived:

- The impact of inlet air temperature and flow rate on the solidification and melting of the PCM is significant. Larger temperature differences between the PCM and the inlet air are contributory to a faster PCM charging and vice versa. On the other hand, small variations are preferred during the discharging phase to prolong the thermal comfort period. In the case of air flow rate, it can be regulated depending on the charging and discharging requirements. High air flow rates are recommended to complete the PCM solidification in a short time, while low air flow rates are required for gradual extraction of the coolness during the discharging phase. The air flow rate should be adjusted carefully to satisfy the system requirement day and night with lower power use by the fan.

- A compact TES system with thin PCM modules and narrow air flow channels is the best for the acceleration of PCM solidification process during the charging phase than a system with thick PCM and wide channels. However, this would result in a quicker melting and a shorter comfort period during the discharging phase. As the variations in the comfort durations are almost insignificant, particularly in the case of thin PCM, a compact TES configuration could be appropriate for both transition phases. However, higher energy consumption may be required. Thus, the energy consumption by the fan should be considered when selecting the TES geometrical configuration.

- The effect of the TES geometrical configuration on the thermal performance was more obvious in the charging process than the discharging. This may be attributed to the higher air flow rates used for acceleration of the charging process than those allocated for gradual extraction of cooling from the PCM.

Overall, The modular design of the PCM storage permits large flexibility to modulate the capacity according to the cooling requirements. The key remark from the numerical investigation is that the proposed free cooling system is capable of maintaining thermal comfort inside buildings day and night and replace the air conditioning system during the transitional 
839 months, where ambient air temperature at night in the range of $21-24{ }^{\circ} \mathrm{C}$ for up to11 hours

840 duration. For the overheated period (May-October), where a significant cooling demand exists

841 and limited cooling availability at night, the free cooling system is capable of meeting around $84242 \%$ of the total cooling load. Compared to conventional AC systems (COP at an average of 843 2.0), energy savings up to $67 \%$ could be attained. Thus, it is suggested to couple the free cooling 844 system with another natural cooling system such as evaporative cooling, ground cooling or 845 radiative cooling in order to enhance the night cooling storage capacity and hence maintaining 846 all-day thermal comfort during summer conditions of hot arid climates.

847

$848 \quad$ Acknowledgements

849 The authors acknowledge the University of Nottingham in the UK, University of Khartoum in 850 Sudan, and the Ministry of Higher Education and Scientific Research of Sudan for the financial 851 support of this research.

852 
855 1. Zeinelabdein, R., S. Omer, and G. Gan, Critical review of latent heat storage systems 856 for free cooling in buildings. Renewable and Sustainable Energy Reviews, 2018. 82(Part 3): p. 2843-2868.

2. Harjunowibowo, D., et al., Recent active technologies of greenhouse systems - A comprehensive review. Bulgarian Journal of Agricultural Science, 2018. 24(1): p. 158-

860

861

862 170.

3. Nejat, P., et al., A global review of energy consumption, CO2 emissions and policy in the residential sector (with an overview of the top ten CO2 emitting countries).

863

864 Renewable and Sustainable Energy Reviews, 2015. 43: p. 843-862.

865

4. Alabdullatief, A., et al., Green roof and louvers shading for sustainable mosque

5. AUE, Arab Union of Electricity, Statistical bulletin. 2015.

867

6. Boyle, G., Renewable energy. Renewable Energy, by Edited by Godfrey Boyle, pp.

868

869

870

871

872 456. Oxford University Press, May 2004. ISBN-10: 0199261784. ISBN-13: 9780199261789, 2004: p. 456.

7. Mohamed, E., et al., A comprehensive investigation of using mutual air and water heating in multi-functional DX-SAMHP for moderate cold climate. Renewable Energy, 2019. 130: p. 582-600.

8. IEA, CO2 emissions from fuel combustion-highlights, https://www.iea.org/publications/freepublications/publication/CO2EmissionsfromFuel CombustionHighlights2017.pdf, Editor. 2017: International Energy Agency (IEA).

9. Pérez-Lombard, L., J. Ortiz, and C. Pout, A review on buildings energy consumption information. Energy and buildings, 2008. 40(3): p. 394-398.

10. Cabeza, L.F. and A. de Gracia, Thermal energy storage (TES) systems for cooling in residential buildings, in Advances in Thermal Energy Storage Systems. 2015, Elsevier. p. 549-572.

881

882

11. Zalba, B., et al., Free-cooling of buildings with phase change materials. International Journal of Refrigeration, 2004. 27(8): p. 839-849.

884

885

12. Nazir, H., et al., Recent developments in phase change materials for energy storage applications: A review. International Journal of Heat and Mass Transfer, 2019. 129: p. 491-523.

886

887

888

889

890

891

892

13. Regin, A.F., S. Solanki, and J. Saini, Heat transfer characteristics of thermal energy storage system using PCM capsules: a review. Renewable and Sustainable Energy Reviews, 2008. 12(9): p. 2438-2458.

14. Abuelnuor, A., et al. Buildings cooling: An experimental study of Phase Change Materials storage for low energy buildings. in Communication, Control, Computing and Electronics Engineering (ICCCCEE), 2017 International Conference on. 2017. IEEE. 
902

903

904

905

906

907

908

909

910

911

912

913

914

915

916

917

918

919

920

921

922

923

924

925

926

927

928

929

930

931

932

933

934

15. Alizadeh, M. and S.M. Sadrameli, Indoor thermal comfort assessment using PCM based storage system integrated with ceiling fan ventilation: Experimental design and response surface approach. Energy and Buildings, 2019. 188: p. 297-313.

16. Bhamare, D.K., M.K. Rathod, and J. Banerjee, Passive cooling techniques for building and their applicability in different climatic zones-The State of Art. Energy and Buildings, 2019.

17. Iten, M., S. Liu, and A. Shukla, A review on the air-PCM-TES application for free cooling and heating in the buildings. Renewable and Sustainable Energy Reviews, 2016. 61: p. 175-186.

18. Dardir, M., et al., Opportunities and challenges of PCM-to-air heat exchangers (PAHXs) for building free cooling applications -A comprehensive review. Journal of Energy Storage, 2019. 22: p. 157-175.

19. Zeinelabdein, R., S. Omer, and G. Gan, Experimental analysis of a PCM-Air heat exchanger for building cooling in hot-arid climates.

20. Liu, Z., et al., A review on macro-encapsulated phase change material for building envelope applications. Building and Environment, 2018.

21. Omara, A.A.M. and A.A.A. Abuelnour, Improving the performance of air conditioning systems by using phase change materials: A review. International Journal of Energy Research, 2019.

22. Turnpenny, J., D. Etheridge, and D. Reay, Novel ventilation cooling system for reducing air conditioning in buildings.: Part I: testing and theoretical modelling. Applied Thermal Engineering, 2000. 20(11): p. 1019-1037.

23. Marín, J.M., et al., Improvement of a thermal energy storage using plates with paraffingraphite composite. International Journal of Heat and Mass Transfer, 2005. 48(12): p. 2561-2570.

24. Darzi, A.R., et al., Numerical investigation of free-cooling system using plate type PCM storage. International Communications in Heat and Mass Transfer, 2013. 48: p. 155163.

25. Arkar, C., B. Vidrih, and S. Medved, Efficiency of free cooling using latent heat storage integrated into the ventilation system of a low energy building. International Journal of Refrigeration, 2007. 30(1): p. 134-143.

26. Panchabikesan, K., et al., Influence of PCM thermal conductivity and HTF velocity during solidification of PCM through the free cooling concept-A parametric study. Journal of Energy Storage, 2019. 21: p. 48-57.

27. Solgi, E., et al., A parametric study of phase change material behaviour when used with night ventilation in different climatic zones. Building and Environment, 2019. 147: p. 327-336.

28. Osterman, E., et al., Parametrical analysis of latent heat and cold storage for heating and cooling of rooms. Applied Thermal Engineering, 2015. 84: p. 138-149.

29. Waqas, A. and S. Kumar, Thermal performance of latent heat storage for free cooling of buildings in a dry and hot climate: An experimental study. Energy and Buildings, 2011. 43(10): p. 2621-2630. 
30. Waqas, A. and S. Kumar, Utilization of latent heat storage unit for comfort ventilation of buildings in hot and dry climates. International Journal of Green Energy, 2011. 8(1): p. 1-24.

31. Muthuvelan, T., et al., Experimental investigation of free cooling using phase change material-filled air heat exchanger for energy efficiency in buildings. Advances in Building Energy Research, 2016: p. 1-11.

32. Zeinelabdein, R., S. Omer, and G. Gan, Experimental performance of latent thermal energy storage for sustainable cooling of buildings in hot-arid regions. Energy and Buildings, 2019.

33. Panchabikesan, K., et al., Feasibility study on the year-round operation of PCM based free cooling systems in tropical climatic conditions. Energy, 2020. 192: p. 116695.

34. Lamberg, P., Mathematical modelling and experimental investigation of melting and solidification in a finned phase change material storage. 2003: Helsinki University of Technology.

35. Voller, V. and M. Cross, Accurate solutions of moving boundary problems using the enthalpy method. International journal of heat and mass transfer, 1981. 24(3): p. 545556.

36. Date, A.W., A strong enthalpy formulation for the Stefan problem. International journal of heat and mass transfer, 1991. 34(9): p. 2231-2235.

37. Yao, M. and A. Chait, An alternative formulation of the apparent heat capacity method for phase-change problems. Numerical Heat Transfer, Part B Fundamentals, 1993. 24(3): p. 279-300.

38. Poirier, D. and M. Salcudean, On numerical methods used in mathematical modeling of phase change in liquid metals. 1988.

39. Kuznik, F., K. Johannes, and D. David, Integrating phase change materials (PCMs) in thermal energy storage systems for buildings, in Advances in Thermal Energy Storage Systems. 2015, Elsevier. p. 325-353.

40. Iten, M., S. Liu, and A. Shukla, Experimental validation of an air-PCM storage unit comparing the effective heat capacity and enthalpy methods through CFD simulations. Energy, 2018. 155: p. 495-503.

41. Zhang, Y., et al., An experimental method for validating transient heat transfermathematical models used for phase change materials (PCMs) calculations. Phase Transitions, 2014. 87(6): p. 541-558.

42. Allouche, Y., et al., Validation of a CFD model for the simulation of heat transfer in a tubes-in-tank PCM storage unit. Renewable Energy, 2016. 89: p. 371-379.

43. Voller, V., A. Brent, and K. Reid, Computational Modelling Framework for Analysis of Metallurgical Solidification Processes and Phenomena. The Institute of Metals, 1988: p. 378-380.

44. Voller, V.R. and C. Prakash, A fixed grid numerical modelling methodology for convection-diffusion mushy region phase-change problems. International Journal of Heat and Mass Transfer, 1987. 30(8): p. 1709-1719.

45. Wang, P., et al., Thermal energy charging behaviour of a heat exchange device with a zigzag plate configuration containing multi-phase-change-materials (m-PCMs). Applied energy, 2015. 142: p. 328-336. 
1002

1003

1004

1005

1006

1007

1008

1009

1010

1011

1012

1013

1014

1015

1016

1017

1018

46. Silva, T., et al., Thermal performance of a window shutter containing PCM: Numerical validation and experimental analysis. Applied Energy, 2016. 179: p. 64-84.

47. Osman, M.M. and H. Sevinc, Adaptation of climate-responsive building design strategies and resilience to climate change in the hot/arid region of Khartoum, Sudan. Sustainable Cities and Society, 2019. 47: p. 101429.

48. Peel, M.C., B.L. Finlayson, and T.A. McMahon, Updated world map of the KöppenGeiger climate classification. Hydrology and earth system sciences discussions, 2007. 4(2): p. 439-473.

49. WMO. World Meteorological Organization. 2016 [cited 2016 12/5]; Available from: http://worldweather.wmo.int/en/city.html?cityId=249 ftp://ftp.atdd.noaa.gov/pub/GCOS/WMONormals/TABLES/REG_I/SU/62721.TXT.

50. Raj, V.A.A. and R. Velraj, Review on free cooling of buildings using phase change materials. Renewable and Sustainable Energy Reviews, 2010. 14(9): p. 2819-2829.

51. Zeinelabdein, R., et al., Free cooling using phase change material for buildings in hotarid climate. International Journal of Low-Carbon Technologies, 2018. 13(4): p. 327337.

52. RUBITHERM. [cited 2017, 09/11]; Available from: [〈https://www.rubitherm.eu/>].

53. Zeinelabdein R., O.S., Mohamed E., Amaireh I., Gan G, Free cooling based phase change material for domestic buildings in hot arid climate, in 16th International Conference on Sustainable Energy Technologies - SET 2017. 2017: Bologna, Italy.

54. Kim, S.-E., D. Choudhury, and B. Patel, Computations of complex turbulent flows using the commercial code FLUENT, in Modeling complex turbulent flows. 1999, Springer. p. 259-276.

55. Shih, T., A New-Eddy-Viscosity Model for High Reynolds Number Turbulent FlowsModel Development and Validation/T.-H. Shih, WW Liou, A. Shabbir, Z. Yang, J. Zhu. Computers Fluids, 1995(24): p. 3.

56. FLUENT, A., 15-Theory Guide, ANSYS. Inc., Canonsburg, PA, 2013.

57. Henningson, D.S. and M. Berggren, Fluid dynamics: Theory and computation. 2005.

58. CIBSE, G.A., Environmental design. The Chartered Institution of Building Services Engineers, London, 2006.

59. Arkar, C. and S. Medved, Free cooling of a building using PCM heat storage integrated into the ventilation system. Solar Energy, 2007. 81(9): p. 1078-1087.

60. Medved, S. and C. Arkar, Correlation between the local climate and the free-cooling potential of latent heat storage. Energy and Buildings, 2008. 40(4): p. 429-437.

61. Munson, B.R., et al., Fluid mechanics. 2013: Wiley Singapore.

62. Franconi, E.M. and J.B. Bradford, 4.3 Ventilation and Air Handling Systems. Handbook of Heating, Ventilation, and Air Conditioning, 2000: p. 67.

63. Mosaffa, A., et al., Thermal performance of a multiple PCM thermal storage unit for free cooling. Energy Conversion and Management, 2013. 67: p. 1-7. 
1019

1020

1021

1022

1023

1024
64. Xiang, Y. and G. Gan, Optimization of building-integrated photovoltaic thermal air system combined with thermal storage. International Journal of Low-Carbon Technologies, 2015. 10(2): p. 146-156.

65. Duan, Z., Investigation of a novel dew point indirect evaporative air conditioning system for buildings. 2011, University of Nottingham. 